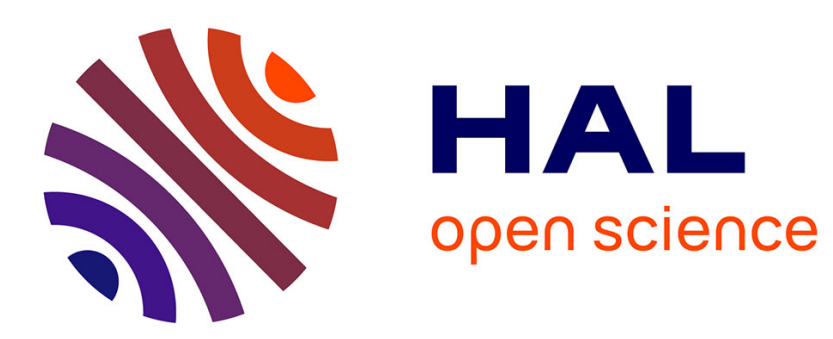

\title{
Impact of Polyethylenimine Conjugation Mode on the Cell Transfection Efficiency of Silica Nanovectors
} Xiaolin Wang, Sylvie Masse, Guillaume Laurent, Christophe Hélary, T. Coradin

\section{- To cite this version:}

Xiaolin Wang, Sylvie Masse, Guillaume Laurent, Christophe Hélary, T. Coradin. Impact of Polyethylenimine Conjugation Mode on the Cell Transfection Efficiency of Silica Nanovectors. Langmuir, 2015, 31 (40), pp.11078-11085. 10.1021/acs.langmuir.5b02616 . hal-01274327

\section{HAL Id: hal-01274327 \\ https://hal.science/hal-01274327}

Submitted on 1 Oct 2018

HAL is a multi-disciplinary open access archive for the deposit and dissemination of scientific research documents, whether they are published or not. The documents may come from teaching and research institutions in France or abroad, or from public or private research centers.
L'archive ouverte pluridisciplinaire HAL, est destinée au dépôt et à la diffusion de documents scientifiques de niveau recherche, publiés ou non, émanant des établissements d'enseignement et de recherche français ou étrangers, des laboratoires publics ou privés. 


\title{
Impact of Polyethyleneimine Conjugation Mode on the Cell Transfection Efficiency of Silica Nanovectors
}

\author{
Xiaolin Wang, Sylvie Masse, Guillaume Laurent, Christophe Hélary,* and Thibaud \\ Coradin* \\ Sorbonne Universités, UPMC Univ Paris 06, CNRS, UMR 7574, Laboratoire de Chimie de \\ la Matière Condensée de Paris, F-75005 Paris, France
}

\begin{abstract}
The conjugation of polyethyleneimine (PEI) to silica nanoparticles has emerged as a useful strategy in gene delivery. Here we investigate the influence of the PEI conjugation mode on the transfection ability of plain silica nanoparticles. Surface functionalization with sulfonate- and chloride-bearing silanes modulates the amount and conformation of PEI, and therefore the particles' affinity for the plasmid, without impacting on cytotoxicity. However, transfection efficiency in both immortalized and primary cells is more directly correlated to the nature and strength of the particle-PEI interactions. It suggests that PEI detachment from the particle surface at the stage of endosomal escape is a key event in the plasmid delivery process. These data should provide fruitful guidelines for the fine tuning of colloidal surfaces intended for intracellular delivery of bioactive molecules.
\end{abstract}




\section{INTRODUCTION}

Gene therapy is considered as a breakthrough in regenerative medicine as it permits to correct genetic disorders. ${ }^{1,2}$ More recently, gene delivery strategies have been used to modulate impaired gene expressions observed in chronic diseases. ${ }^{3,4}$ In this case, therapeutic genes do not need to be inserted in the genome but are transitory expressed. Therapeutic genes can take the form of shRNA, siRNA or plasmidic DNA. ${ }^{5-7}$ Because of their negative charge, nucleic acids are unable to penetrate into the cells. As a consequence, they need to be combined with a transfecting reagent to penetrate the mammalian cells. Viral vectors are broadly used as they present the highest transfection efficiencies. ${ }^{8}$ Nonetheless, these systems have several limitations such as their immunogenicity and oncogenicity. ${ }^{9}$ These drawbacks justified the development of non-viral vectors such polymeric transfecting reagents. ${ }^{9}$ PEI has been deemed as one of the most efficient polymeric transgene reagent in virtue of the 'proton sponge effect', that enables endosomal escape and translocation of DNA into the nucleus. ${ }^{10}$ However, the cytotoxicity accompanying high transfection efficiency greatly impairs its clinical 
applications. Efforts have been devoted to find a compromise between the two phenomena, by chemical modification of PEI or its conjugation to nanoparticles. ${ }^{11}$

Nanoscale delivery systems hold great promise for gene therapy owing to their ability to enhance cellular uptake and intracellular stability of nucleic acids. ${ }^{12}$ For gene delivery, the generation of positive charges on the particle external or internal surface is required to complex negatively-charged nucleic acids. A common solution is to modify nanoparticle surface with amino-alkoxysilane ${ }^{3}$ or cationic polymers, ${ }^{13-16}$ among which polyethyleneimine (PEI) has drawn considerable interest. The combination of particles with PEI was first studied to promote polyplex transfection efficiency, in which nanoparticles was applied to enhance sedimentation of polyplexes at cell surface. Silica nanoparticles have emerged as ideal candidates due to their biocompatibility, facile fabrication, tunable size/porosity and easy surface functionalization. ${ }^{17}$ Silica nanoparticles were first studied as drug delivery systems to target tumoral cells or to deliver antibiotics inside the cells. ${ }^{18,19}$ For example, several studies have shown the delivery of high doses of doxorubicin within multi-resistant cancer cells. ${ }^{20} \mathrm{SiO}_{2}$-PEI particles have emerged as versatile drug/gene vehicles that can be synthesized by in situ polymerization, ${ }^{21}$ electrostatic adsorption ${ }^{22}$ and covalent bonding. ${ }^{23}$ However the impact of the PEI bioconjugation mode to silica particles on its conformation and on the carrier transfection efficiency has not been examined so far.

To address this question, we have compared here three methods to conjugate PEI with plain silica nanoparticles, from non-specific electrostatic interactions to covalent bonding 
(Figure 1). We show that the mode of conjugation impacts on the amount and conformation of immobilized PEI and that the transfection efficiency is directly related to the nature of the particle-PEI interactions, both in immortalized fibroblasts and primary keratinocytes. These results have important implications for the design of nanovectors for intracellular drug delivery.

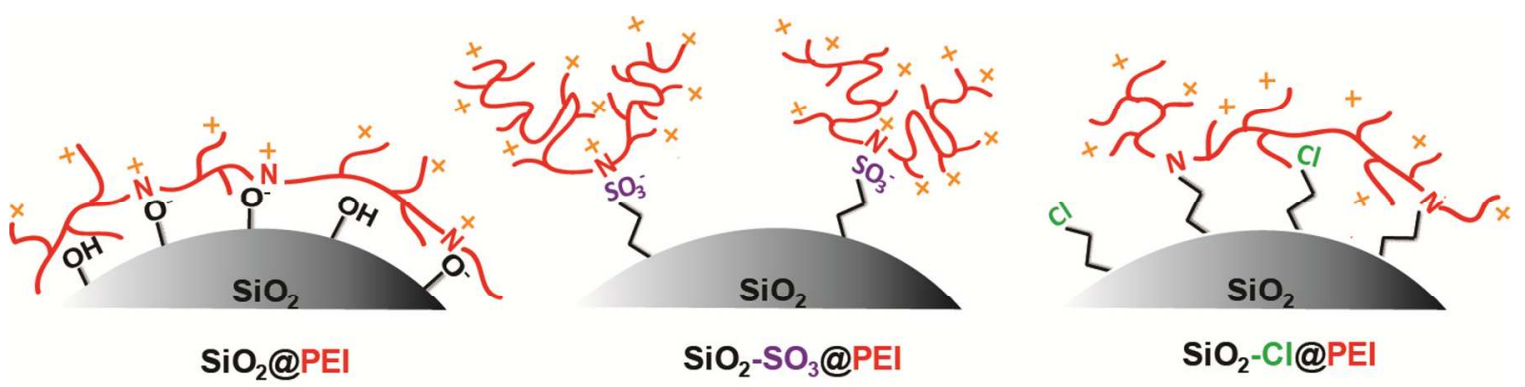

Figure 1. Schematic representation of the different conjugation modes of polyethyleneimine (PEI) with silica particles and proposed PEI configuration: non-specific adsorption on silica particles $\left(\mathrm{SiO}_{2} @ \mathrm{PEI}\right)$, strong electrostatic interactions with sulfonate-modified silica particles $\left(\mathrm{SiO}_{2}-\mathrm{SO}_{3} @ \mathrm{PEI}\right)$ and covalent bond with propylchloride-grafted silica particles $\left(\mathrm{SiO}_{2}-\mathrm{Cl} @ \mathrm{PEI}\right)$.

\section{MATERIALS AND METHODS}

Silica-polyethyleneimine particle preparation. Silica nanoparticles $\mathrm{SiO}_{2}$ were synthesized by the Stöber method ${ }^{24}$ using $7.6 \mathrm{~mL}$ of tetraethylorthosilicate (TEOS), 200 $\mathrm{mL}$ of ethanol, $9.7 \mathrm{~mL}$ of ammonia $(25 \%)$ and $5.9 \mathrm{~mL}$ of deionized water. For $\mathrm{SiO}_{2} @$ PEI particle preparation, $200 \mathrm{mg}$ of branched polyethyleneimine PEI (25 kDa) was 
dissolved in $20 \mathrm{~mL}$ of saline phosphate buffered saline (PBS, $10 \mathrm{mM}, \mathrm{pH} \mathrm{7.4).}{ }^{25}$ Silica nanoparticle suspension in PBS $(20 \mathrm{~mL})$ was then added dropwise into the PEI solution under stirring. The mixtures were stirred for $48 \mathrm{~h}$ after which particles were recovered by centrifugation, washed 3 times in PBS and finally suspended in PBS.

For $\mathrm{SiO}_{2}-\mathrm{SO}_{3} @ \mathrm{PEI}$ particle preparation, the SiNP was first functionalized with thiol groups by silylation with 3-mercaptoptopyltrimethoxysilane (MPTMS). ${ }^{26}$ Typically, $1 \mathrm{~g}$ of silica was dispersed in a mixture of $100 \mathrm{~mL}$ ethanol and $2.2 \mathrm{~mL}$ ammonium hydroxide solution before addition of $1 \mathrm{~mL}$ MPTMS. The mixture was stirred for $40 \mathrm{~min}$ at room temperature. Subsequently, the reaction mixture was heated to $80^{\circ} \mathrm{C}$ and the total volume was reduced by $2 / 3$ by distillation of ethanol and ammonia at ambient pressure. Then, the mixture was cooled back to room temperature, centrifuged, washed 3 times with ethanol and dried at $60{ }^{\circ} \mathrm{C}$. Then $0.9 \mathrm{~g}$ of the thus-obtained $\mathrm{SiO}_{2}-\mathrm{SH}$ was suspended in $45 \mathrm{~mL}$ hydrogen peroxide $\left(\mathrm{H}_{2} \mathrm{O}_{2} 35 \%\right.$, Acros Organics $)$ under stirring at room temperature for 48 hours. The solid product was washed by centrifugation with distilled water before addition of $35 \mathrm{~mL}$ of concentrated sulfuric acid $\left(\mathrm{H}_{2} \mathrm{SO}_{4} 95.0-98.0 \%\right.$, Sigma Aldrich) and stirred for 2 hours. Finally the as-synthesized $\mathrm{SiO}_{2}-\mathrm{SO}_{3}$ particles were washed with water, suspended in PBS and coated with PEI as described above.

For $\mathrm{SiO}_{2}-\mathrm{Cl} @ \mathrm{PEI}$ particle preparation, 400 mg of $\mathrm{SiO}_{2}$ nanoparticles was dispersed in $20 \mathrm{~mL}$ of dried toluene, and $1.3 \mathrm{~mL}$ of chloropropyltriethoxysilane (Cl-PTES) was added to the suspension, that was further kept under reflux for $24 \mathrm{~h}$, after which the 
product was washed thoroughly with toluene and ethanol, and dried at room temperature.

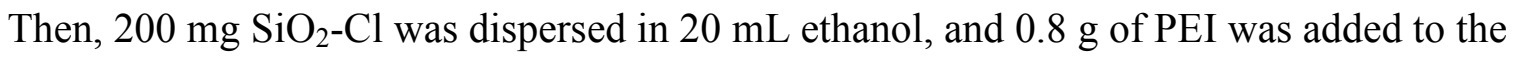
suspension. The suspension was refluxed for $24 \mathrm{~h}$. The final solid product was recovered by washing with ethanol and dried at room temperature. The as-synthesized SiNP-Cl@PEI was suspended in 10 mM PBS before use.

Silica-polyethyleneimine particle characterization. Sizes and zeta potential $(\zeta)$ were measured in $10 \mathrm{mM}$ PBS solution using a ZetaSizer Nano (Malvern Instruments Ltd., Worcestershire, UK). Particles were also imaged using Transmission Electron Microscopy (TEM) on a JEOL 1011 instrument. The amount of adsorbed PEI was determined by elemental analysis $(\mathrm{C}, \mathrm{H}, \mathrm{O}, \mathrm{N})$. For $\mathrm{SiO}_{2}-\mathrm{SO}_{3}$, the grafting rate was calculated according to the amount of - $\mathrm{SH}$ before oxidation, which is determined by Ellman test. ${ }^{27}$ For this test, a phosphate buffer $(0.2 \mathrm{M}, \mathrm{pH}=7.3)$ was prepared and labeled as solution A. Solution B (10 mM EDTA) was produced by dissolving $372 \mathrm{mg}$ of EDTA in $100 \mathrm{~mL}$ of solution $\mathrm{A}$, and solution $\mathrm{C} \quad(6 \mathrm{mM}$ 5-(3-Carboxy-4-nitrophenyl)disulfanyl-2-nitrobenzoic acid (DTNB)) was prepared by dissolving $238 \mathrm{mg}$ of DTNB in $100 \mathrm{~mL}$ of solution A. Several vials were filled with a mixture of $8 \mathrm{ml}$ of solution $\mathrm{A}, 1 \mathrm{~mL}$ of solution $\mathrm{B}$ and $1 \mathrm{~mL}$ of solution $\mathrm{C}$. A series of masses of $\mathrm{SiO}_{2}-\mathrm{SH}$, less than $50 \mathrm{mg}$, were measured and then each dispersed into a vial mixture solution. Simultaneously, several known quantities of thiol (obtained from a solution of MPTMS) were also introduced in the same mixture solution to determine the 
molar extinction coefficient by linear regression. After 45 minutes of stirring, the particle dispersion is filtered through a syringe filter. The absorbance of the filtrate and standard MPTMS solutions are determined by spectroscopy. The absorbance of the solutions MTPMS can be traced back to the value for the experience of the molar extinction coefficient of $\mathrm{NTB}^{2-}$ by linear regression.

XPS analyses of the powders were performed on a Phoibos 100 X-ray photoelectron spectrometer (SPECS GmbH, Germany) with the Mg K? X-ray source (hv=1253.6 eV). Spectra were recorded with $20 \mathrm{eV}$ pass energy for the survey scan and with $10 \mathrm{eV}$ pass energy for the C 1s, O 1s, N 1s, S 2s and Si 2 p regions. A take-off angle of $90 \circ$ from the surface was employed. Element peak intensities were corrected by Scofield factors and the spectra were fitted using the Casa XPS v.2.3.13 Software (Casa software Ltd. UK) and by applying a Gaussian/Lorentzian ratio, G/L equal to 70/30.

pDNA-PEI and pDNA-PEI-SiNP Complexation. Reporter plasmid pCMV-GLuc (pGluc) encoding for Gaussia Luciferase (New England BioLabs, Ipswich, MA) was used to quantify transgene expression. This plasmid was amplified by one shot ${ }^{\circledR}$ BL21(DE3) pLysS kit (Invitrogen ${ }^{\mathrm{TM}}$, Life technologies), extracted by one PureLink ${ }^{\circledR}$ HiPure Plasmid kit (Invitrogen ${ }^{\mathrm{TM}}$, Life technologies) and finally stored in Tris-EDTA buffer at $-20{ }^{\circ} \mathrm{C}$. pGluc-PEI complexes were prepared at weight ratio of 1:2. pGluc$\mathrm{SiO}_{2} \mathrm{X} @ \mathrm{PEI}\left(\mathrm{X}=\right.$ none, $\left.\mathrm{SO}_{3}, \mathrm{Cl}\right)$ complexes were prepared at various weight ratios. Complexes formation was examined by agarose gel electrophoresis. Briefly, $1 \mu \mathrm{L}$ of 
pGluc solution $\left(0.1 \mu \mathrm{g} . \mu \mathrm{L}^{-1}\right)$ were mixed homogeneously with a total volume of $9 \mu \mathrm{L}$ of $\mathrm{SiO}_{2}$-X@PEI suspension or PEI solution (PBS 1x) by vortexing in a microcentrifuge tube. The resulting mixtures were left at room temperature for $2 \mathrm{~h}$ to achieve complete complexation, before being loaded onto $0.7 \%$ agarose gel with ethidium bromide $(0.1$ $\mu \mathrm{g} . \mathrm{mL}^{-1}$ ) and running with TAE buffer at $100 \mathrm{~V}$ for $40 \mathrm{~min}$. DNA retardation was observed by irradiation with ultraviolet light.

Cell Transfection and Cell Viability. 3T3 mouse fibroblasts were cultured in complete cell culture medium (Dulbecco's Modified Eagle's Medium (DMEM) supplemented with $10 \%$ fetal serum, $100 \mathrm{U} \cdot \mathrm{mL}^{-1}$ penicillin, $100 \mu \mathrm{g} \cdot \mathrm{mL}^{-1}$ streptomycin and $0.25 \mu \mathrm{g} \cdot \mathrm{mL}^{-1}$ Fungizone). Primary normal human keratinocytes (NHK) were cultured in keratinocytes growth medium 2 (Promocell) supplemented with $\mathrm{CaCl}_{2}$. Tissue culture flasks $\left(75 \mathrm{~cm}^{2}\right)$ were kept at $37{ }^{\circ} \mathrm{C}$ in a $95 \%$ air: $5 \% \mathrm{CO}_{2}$ atmosphere. Before confluence, cells were removed from culture flasks by treatment with $0.1 \%$ trypsin and $0.02 \%$ EDTA. Cells were rinsed and suspended in the appropriate culture medium before use.

Transfection efficiency of pGluc-PEI and pGluc-SiO 2 -X@PEI were evaluated by luciferase expression of pGLuc by cells in cell culture medium. To perform cell transfection, mouse fibroblasts or human keratinocytes were plated at a density of $5.10^{4}$ per well in a 24-well plate. pGluc-PEI or pGluc-SiO 2 -X@PEI complexes $(25 \mu \mathrm{L})$ were added to the cell culture medium. After $4 \mathrm{~h}$, the supernatant was removed, the well was 
refreshed with $1 \mathrm{~mL}$ medium and the cells were then cultured for another $44 \mathrm{~h}$ in complete medium for the expression of luciferase. For measurements of luciferase activity, a BioLux Gaussia Luciferase Assay Kit (New England Biolabs) was used and transgene expression of luciferase was reported as relative light units (RLU). Control groups were under the same culture condition as the experiment groups except for the absence of DNA complexes.

Internalization of nanoparticles in 3T3 mouse fibroblasts was studied using fluorescence microscopy. Fluorescent silica particles $200 \mathrm{~nm}$ in diameter were prepared according to a previously described $\operatorname{protocol}^{28}$ and modified according to the above-described procedure. The pGluc-fluorescent nanoparticles complexes along with cell culture medium were removed after a $24 \mathrm{~h}$ incubation period, rinsed 3 times with PBS and fixed with 4\% paraformaldehyde for 1 hour at room temperature. The cell nucleus was then stained with DAPI (4',6-diamidino-2-phenylindole dihydrochloride, Life technologies, $300 \mathrm{nM}$ in PBS) for $10 \mathrm{~min}$ and rinsed with PBS before observation.

Cell viability was monitored using the Alamar Blue test. For the 2D model, cell culture medium was removed for luciferase activity test and $200 \mu \mathrm{L}$ of the Alamar Blue solution $\left(10 \%\right.$ in cell culture medium) was added. The cells were then incubated at $37{ }^{\circ} \mathrm{C}$ with $5 \% \mathrm{CO}_{2}$ for $4 \mathrm{~h}$. The supernatant in each well was then collected, diluted with 800 $\mu \mathrm{L}$ water, and its absorbance was measured at $\lambda=570 \mathrm{~nm}$ and $600 \mathrm{~nm}$. Cell viability was calculated and reported as a percentage of the control group $(n=6)$. 


\section{RESULTS AND DISCUSSION}

Chemical properties of PEI-coated silica nanoparticles. Silica nanoparticles $\mathrm{SiO}_{2}$ were synthesized by the Stöber method and obtained with a low size dispersity $(210 \pm 20$ $\mathrm{nm}$, from TEM with a polydispersity index PDI = 0.005) $($ Figure S1). After coating with PEI, the particle hydrodynamic diameter $(d)$ in PBS was not significantly modified but the PDI significantly increased to 0.127 . The zeta potential $(\zeta)$ value turned from negative to positive in PBS, in agreement with the deposition of a cationic polymer (Table 1). In the case of sulfonated $\mathrm{SiO}_{2}-\mathrm{SO}_{3}$ particles, neither surface functionalization nor PEI sorption significantly impacted on the colloidal size distribution. The mean $\zeta$ value of $\mathrm{SiO}_{2}-\mathrm{SO}_{3}$ particles was slightly more negative than for bare silica, due to the presence of acidic sulfonate moieties, but the $\zeta$ value after PEI coating was similar for both particles. The $\mathrm{SiO}_{2}-\mathrm{Cl}$ nanoparticles showed a high tendency to aggregate, as such and after PEI conjugation, with high PDIs in both situations. However, the $\zeta$ values were not significantly different from the two previous systems (Table 1).

Elemental analysis allowed for quantification of grafted moieties and amount of surface PEI (Table 1). For $\mathrm{SiO}_{2}-\mathrm{SO}_{3}$, the $\mathrm{S}$ content was below $0.1 \mathrm{wt} \%$ so that the silane density was obtained by the Ellman test, yielding to $c a .1 .5 \times 10^{4}$ groups per particle. For $\mathrm{SiO}_{2}-\mathrm{Cl}$, grafting density was estimated to $c a .1 .5 \times 10^{6}$ silanes per particle. Upon reaction with PEI, the $\mathrm{Cl}: \mathrm{Si}$ ratio was decreased by half, supporting the occurrence of a nucleophilic substitution reaction between the propylchloride moieties and amine groups. 
The extent of the alkylation reaction was qualitatively supported by ${ }^{13} \mathrm{C}$ NMR experiments evidencing a significant decrease of the mobility of the $\alpha \mathrm{C}$ of the chloropropyl chain after reaction with PEI (Figure S2). The highest amount of bound PEI was obtained for $\mathrm{SiO}_{2} @$ PEI (12 wt\%) while the two other systems had a significantly lower binding capacity 4 wt $\%$ for $\mathrm{SiO}_{2}-\mathrm{SO}_{3} @ \mathrm{PEI}$ and 3 wt $\%$ for $\left.\mathrm{SiO}_{2}-\mathrm{Cl} @ \mathrm{PEI}\right)$.

Table 1. Hydrodynamic diameter $(d)$ with polydispersity index (PDI), zeta potential $(\zeta)$ in PBS, elemental analysis and calculated composition of the particles.

\begin{tabular}{lcccccccc}
\hline & $d$ & $\zeta$ & $\mathrm{PDI}$ & $\mathrm{Cl}: \mathrm{Si}$ & $\mathrm{N}: \mathrm{Si}$ & $\mathrm{PEI}$ & silane/ & amine/ \\
& $(\mathrm{nm})$ & $(\mathrm{mV})$ & & $(\mathrm{wt} \%)$ & $(\mathrm{wt} \%)$ & $(\mathrm{wt} \%)$ & particle & particle \\
\hline $\mathrm{SiO}_{2}$ & $214 \pm 17$ & $-15 \pm 6$ & 0.005 & - & - & - & - & - \\
$\mathrm{SiO}_{2} @ \mathrm{PEI}$ & $188 \pm 68$ & $+20 \pm 7$ & 0.126 & - & 11.0 & 12.7 & - & $5 \times 10^{6}$ \\
$\mathrm{SiO}_{2}-\mathrm{SO}$ & $233 \pm 38$ & $-21 \pm 8$ & 0.027 & - & - & - & $1.5 \times 10^{4 a}$ & - \\
$\mathrm{SiO}_{2}-\mathrm{SO} @ \mathrm{PEI}$ & $221 \pm 20$ & $+21 \pm 9$ & 0.008 & - & 3.8 & 4.2 & $\mathrm{ND}^{b}$ & $1.5 \times 10^{6}$ \\
$\mathrm{SiO}_{2}-\mathrm{Cl}$ & $518 \pm 308$ & $-13 \pm 6$ & 0.314 & 2.7 & - & - & $1.7 \times 10^{6}$ & - \\
$\mathrm{SiO}_{2}-\mathrm{Cl} @ \mathrm{PEI}$ & $806 \pm 642$ & $+18 \pm 9$ & 0.635 & 1.1 & 3.1 & 3.4 & $\mathrm{ND}^{\mathrm{b}}$ & $10^{6}$ \\
\hline
\end{tabular}

${ }^{a}$ from Ellman titration; ${ }^{b} \mathrm{ND}=$ not determined 

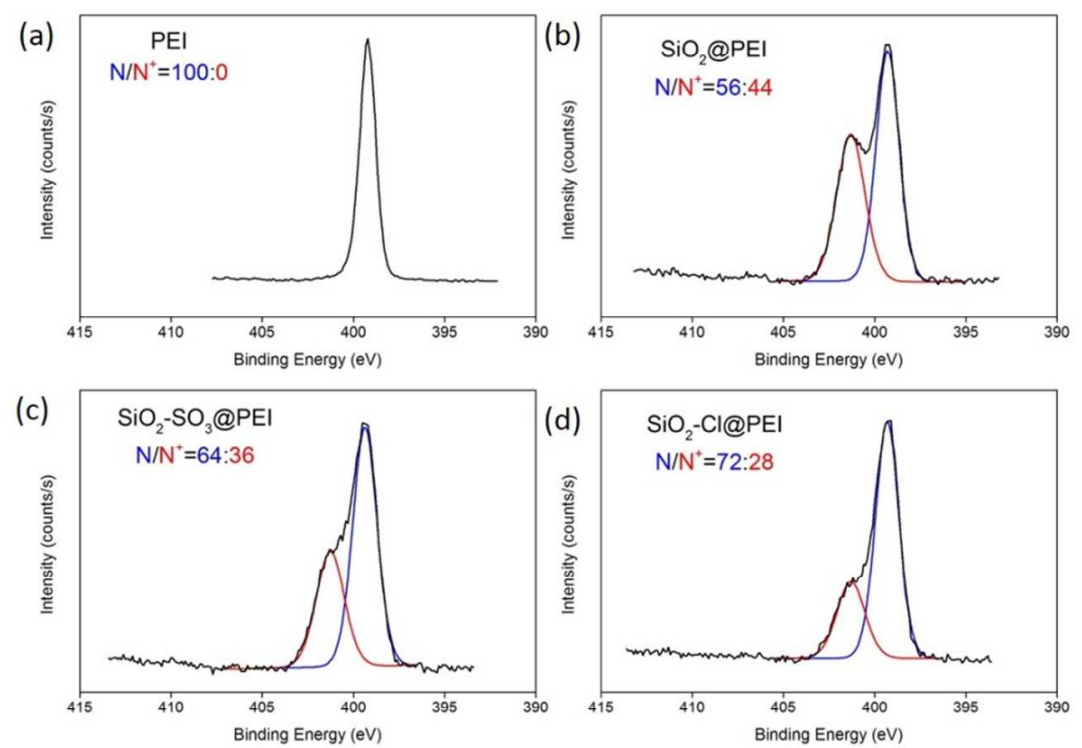

Figure 2: XPS spectra of (a) pure PEI, (b) $\mathrm{SiO}_{2} @ \mathrm{PEI}$, (c) $\mathrm{SiO}_{2}-\mathrm{SO}_{3} @ \mathrm{PEI}$ and (d) $\mathrm{SiO}_{2}-\mathrm{Cl} @ \mathrm{PEI}$ at the $\mathrm{N}_{1 \mathrm{~s}}$ level.

The surface composition of the particles was studied by X-ray Photoelectron Spectroscopy (XPS) (Figure 2 and Figure S3). For PEI, carbon and nitrogen elements are identified in a C:N atomic ratio of 70:30, in fair agreement with the overall $\mathrm{C}_{2} \mathrm{H}_{5} \mathrm{~N}$ formula of ethylene imine. The $\mathrm{C}_{1 \mathrm{~s}}$ data show an asymmetric peak in the 284-288 eV region, corresponding to the overlap of C-C $(285 \mathrm{eV})$ and C-N $(287 \mathrm{eV})$ signals. ${ }^{29}$ The $\mathrm{N}_{1 \mathrm{~s}}$ signal consists of a single peak centered à $399 \mathrm{eV}$ that can be attributed to primary/secondary/tertiary amines. For $\mathrm{SiO}_{2}$, the typical peaks of amorphous silica are observed at $103 \mathrm{eV}\left(\mathrm{Si}_{2 \mathrm{p}}\right)$ and $534 \mathrm{eV}\left(\mathrm{O}_{1 \mathrm{~s}}\right){ }^{30} \mathrm{~A}$ weak $\mathrm{C}_{1 \mathrm{~s}}$ signal is also obtained that can be attributed to carbon surface contamination as well as possible unhydrolyzed $\mathrm{Si}\left(\mathrm{OC}_{2} \mathrm{H}_{5}\right)$ 
moieties. The XPS spectrum of $\mathrm{SiO}_{2} @$ PEI particles combines the $\mathrm{Si}, \mathrm{O}$ and $\mathrm{C}$ peaks of $\mathrm{SiO}_{2}$ and PEI. However, the $\mathrm{N}_{1 \mathrm{~S}}$ data showed two populations at $399 \mathrm{eV}$ and $401 \mathrm{eV}$ in a 56:44 intensity ratio, the latter corresponding quartenary amines (Figure 2). ${ }^{31}$ The presence of sulfonate groups could be ascertained by the presence of a $\mathrm{S}_{2 \mathrm{~s}}$ signal at $232 \mathrm{eV}$ for $\mathrm{SiO}_{2}-\mathrm{SO}_{3} \cdot{ }^{32}$ Compared to $\mathrm{SiO}_{2}$, the $\mathrm{C}_{1 \mathrm{~s}}$ region showed an additional signal near $289 \mathrm{eV}$ that can be attributed to the C-S bond. PEI coating did not significantly modify the C, O, Si and S signals. At the $\mathrm{N}_{1 \mathrm{~s}}$ level, the $399 \mathrm{eV}$ and $401 \mathrm{eV}$ peaks are again identified but with an intensity ratio of 64:36 (Figure 2). For $\mathrm{SiO}_{2}-\mathrm{Cl}$, the $\mathrm{Cl}_{2 \mathrm{p}}$ peak near $200 \mathrm{eV}$ confirms the successful grafting of Cl-PTES. ${ }^{33}$ Similarly to $\mathrm{SiO}_{2}-\mathrm{SO}_{3}$, the $\mathrm{C}_{1 \mathrm{~s}}$ signal shows a high energy contribution corresponding to $\mathrm{C}-\mathrm{Cl}$ bond. For $\mathrm{SiO}_{2}-\mathrm{Cl} @ \mathrm{PEI}$, the $\mathrm{Cl}_{2 \mathrm{p}}$ signal was still clearly evidenced but a slight decrease of the $\mathrm{Cl}$ :Si ratio was found, in qualitative agreement with the elemental analysis results. The signal at the $\mathrm{N}_{1 \mathrm{~s}}$ level indicates a unprotonated:protonated amine ratio of 72:28 (Figure 2), the highest value in this series.

Using the reporter plasmid pCMV-GLuc (pGluc), the optimal plasmid:particle ratio was determined using gel electrophoresis (Figure 3). Full retention was achieved for pG-Luc:SiO ${ }_{2} @$ PEI and pG-Luc:SiO ${ }_{2}-\mathrm{SO}_{3} @$ PEI: weight ratios of 1:30 whereas a 1:50 ratio was optimal for pGLuc: $\mathrm{SiO}_{2}-\mathrm{Cl} @$ PEI. As a comparison, the optimal pG-Luc:PEI ratio was $1: 2$. 


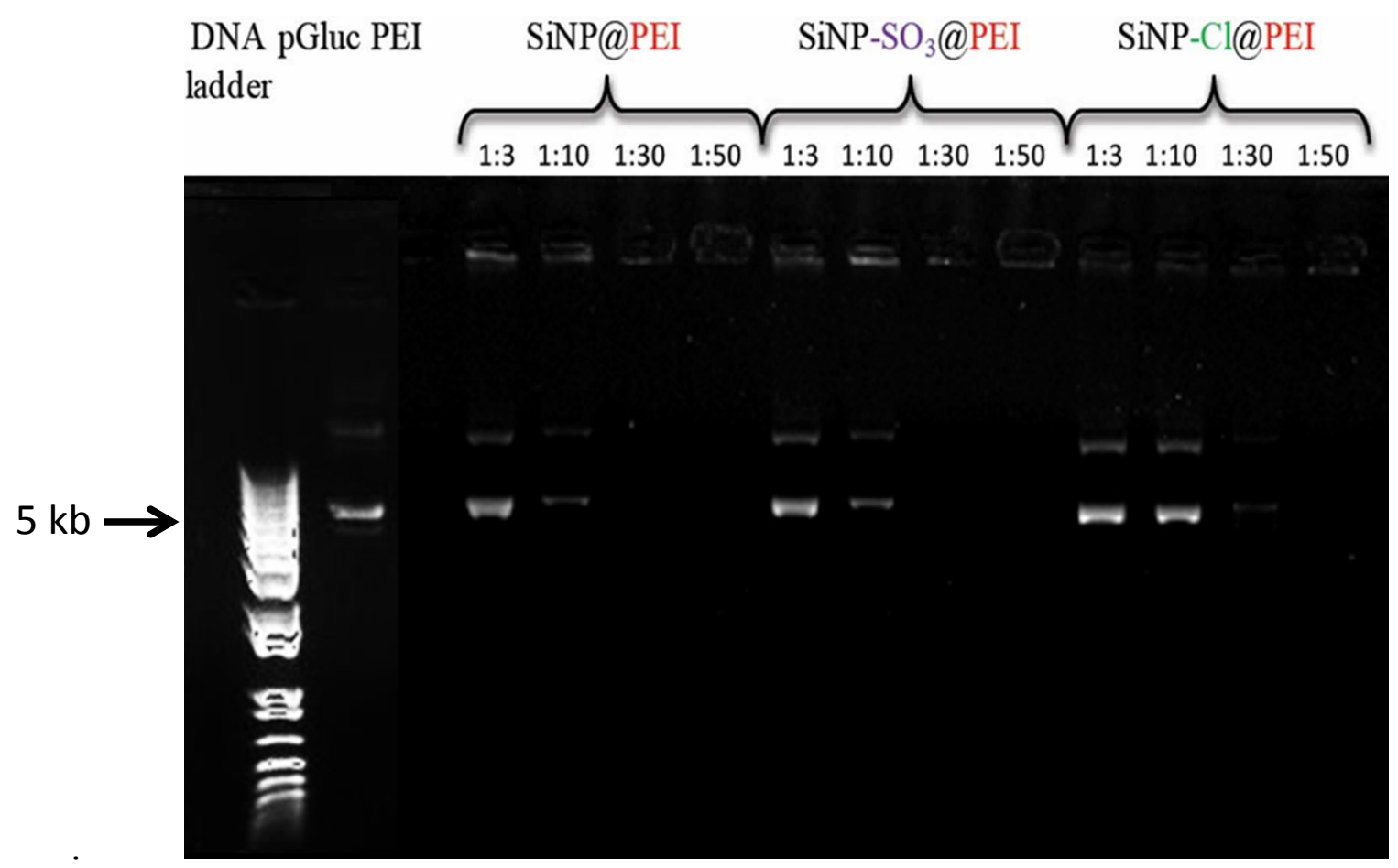

Figure 3: Agarose gel electrophoresis showing the influence of PEI conjugation mode on pGLuc complexation. A constant amount of pGLuc was complexed with particles at 1:3, $1: 10,1: 30$ and $1: 50$ weight ratios.

These data indicate that the conjugation mode impacts on PEI content, charge and plasmid binding ability. For $\mathrm{SiO}_{2} @ \mathrm{PEI}$, using a particle radius of $100 \mathrm{~nm}$ and a silica density of 2 g.cm ${ }^{-3}$, the total amount of amine groups per particle can be estimated to ca. $5.10^{6}$ from elemental analysis (Table 1). The ammonium/total amine ratio obtained by XPS is $c a .45 \%$ (i.e. $c a .2 .2 \times 10^{6}$ ammonium per particle). As a comparison a $30 \%$ value was reported for PEI in a buffer solution ( $\mathrm{pH} 7.4)$, suggesting that partial PEI protonation occurred during the adsorption process. ${ }^{34}$ A density of 3-5 silanol per $\mathrm{nm}^{2}$ was reported for amorphous silica surfaces, i.e. $4-6 \times 10^{5} \mathrm{SiOH}$ for $200 \mathrm{~nm}$ particles, with $20 \%$ of acidic 
$(\mathrm{pKa}=4.5)$ and $80 \%$ of basic $(\mathrm{pKa}=8.5)$ groups. $^{35}$ The increase in PEI protonation may therefore arise from an acid-base reaction with the silanol groups. Comparing $5 \times 10^{5} \mathrm{SiOH}$ with $2.2 \times 10^{6} \mathrm{~N}^{+}$per particle, the silanol:ammonium ratio is $1: 4-5$ so that the positive charge of PEI is not balanced by the negative charge of silica, explaining the positive $\zeta$ value of these systems.

For $\mathrm{SiO}_{2}-\mathrm{SO}_{3} @ \mathrm{PEI}$, the protonation degree of PEI is closer to the reported value in buffer (36\% vs. $30 \%$ ). Sulfonate groups are fully deprotonated at $\mathrm{pH} 7$ so that proton exchange with PEI was not expected. The fact that the silanol groups do not significantly interact with the polymer suggests that PEI is kept apart from the silica surface. Interestingly, combined elemental analysis and XPS indicate that there are $5 \times 10^{5}$ ammonium groups per particle to be compared with $1.5 \times 10^{4}$ sulfonate groups. This observation can be compared with a recent study devoted to the sorption of collagen triple helices on the surface of silica particles. ${ }^{26}$ For bare particles, a large amount of collagen was readily adsorbed, suggesting that the protein adopts a flat configuration on the particle surface. In contrast, sulfonate-bearing particles could adsorb less collagen but the proteins had a more ordered organization. It was suggested that the sulfonate groups could act as anchoring points for the protein chains that protrude out of the surface rather than laying flat, so that the amount of sorbed collagen was limited by the steric constraints of the triple helices packing. A similar situation can be reasonable assumed for the present system (Figure 1). Noticeably, naked particles have a lower initial negative charge, bind more PEI with a higher degree of protonation than sulfonated ones, so that it was expected that 
they exhibit a higher positive surface charge after coating. However the two systems show close $\zeta$ values. This can be explained considering that silanol groups of the surface can contribute to the overall particle charge for $\mathrm{SiO}_{2}$ whereas these moieties are screened by the sulfonate/PEI layer, strengthening our model of a flat vs. compact organization of the polymer in the two systems.

For $\mathrm{SiO}_{2}-\mathrm{Cl} @ \mathrm{PEI}$, the protonation degree of PEI is similar to its free form in buffer and the number of amines per particle is $c a .10^{6}$. This value is in the same range as the initial density of propylchloride groups $\left(1.5 \times 10^{6}\right)$. Elemental analysis indicate that one half of the $\mathrm{Cl}$ atoms are no longer present after reaction with PEI. Taken together these data suggest that an important fraction of the PEI amine groups have reacted with the propylchloride moieties. It is therefore possible to assume that each PEI chain is bound to the particle surface by several anchoring points, decreasing its conformational flexibility and therefore its maximum packing density on the surface, resulting in a low PEI loading (Figure 1). Noticeably, $\mathrm{SiO}_{2}-\mathrm{Cl} @ \mathrm{PEI}$ has a similar $\zeta$ value to $\mathrm{SiO}_{2} @ \mathrm{PEI}$, which can be explained considering that the less negative surface charge of the chlorinated surface compared to bare particles is compensated by lower PEI loading and lower PEI protonation.

Considering the optimal plasmid:PEI ratio, it depends on the positive charge of PEI, as the PEI-plasmid system is a polyelectrolyte complex, as well as on the PEI flexibility, that determines its ability to wrap and compact DNA. ${ }^{10,36}$ The amount of PEI per particle must also be considered for the optimal plasmid:particle ratio. $\mathrm{SiO}_{2} @ \mathrm{PEI}$ and $\mathrm{SiO}_{2}-\mathrm{SO}_{3} @ \mathrm{PEI}$ 
particles have a similar optimal pGLuc:particle@PEI ratio although the former has a higher polymer loading with a larger proportion of ammonium groups than the latter. As pointed out earlier, the $\zeta$ value is not a suitable parameter to compare the complexing ability of the systems as it can include a contribution of the silica particle surface that is not involved in the DNA wrapping process. Rather PEI conformation has to be considered (Figure 1). For $\mathrm{SiO}_{2}$, the extended conformation of the polyelectrolyte is not favorable for DNA wrapping whereas the local anchoring of PEI on the surface of $\mathrm{Si}_{-} \mathrm{SO}_{3}$ should better preserve its structural flexibility. For $\mathrm{SiO}_{2}-\mathrm{Cl}$, as mentioned earlier, its flexibility should be limited by the high density of covalent bonds, resulting in a low pG-Luc:particle@PEI ratio.

\section{Biological properties of PEI-coated silica nanoparticles.}

Delivery of therapeutic genes from PEI-coated silica nanoparticles requires the particles uptake by cells. Particle internalization within mouse 3T3 fibroblasts was checked using fluorescent FITC-silica nanoparticles after $48 \mathrm{~h}$ of contact. Observations by fluorescence microscopy evidenced the accumulation of colloids near the cell nucleus for $\mathrm{SiO}_{2} @ \mathrm{PEI}$ and $\mathrm{SiO}_{2}-\mathrm{Cl} @ \mathrm{PEI}$ (Figure 4A). Bleaching of the FITC probes during sulfonate particle preparation hindered their intracellular observation. Cytotoxicity of uncoated and PEI-coated particles was also studied on $3 \mathrm{~T} 3$ fibroblasts. This study consisted in the measure of cell viability of fibroblasts incubated with increasing doses of particles (Figure 4B). For particle@PEI systems, cell viability was always higher than 80 
$\%$, indicating the absence of significant cytotoxicity up to $50 \mu \mathrm{g} \cdot \mathrm{mL}^{-1}$ in PEI. In contrast, PEI alone was detrimental to cell viability at a dose $>5 \mu \mathrm{g} \cdot \mathrm{mL}^{-1}$. Uncoated particles were evaluated using the same silica weights, showing no visible cytotoxicity effect.

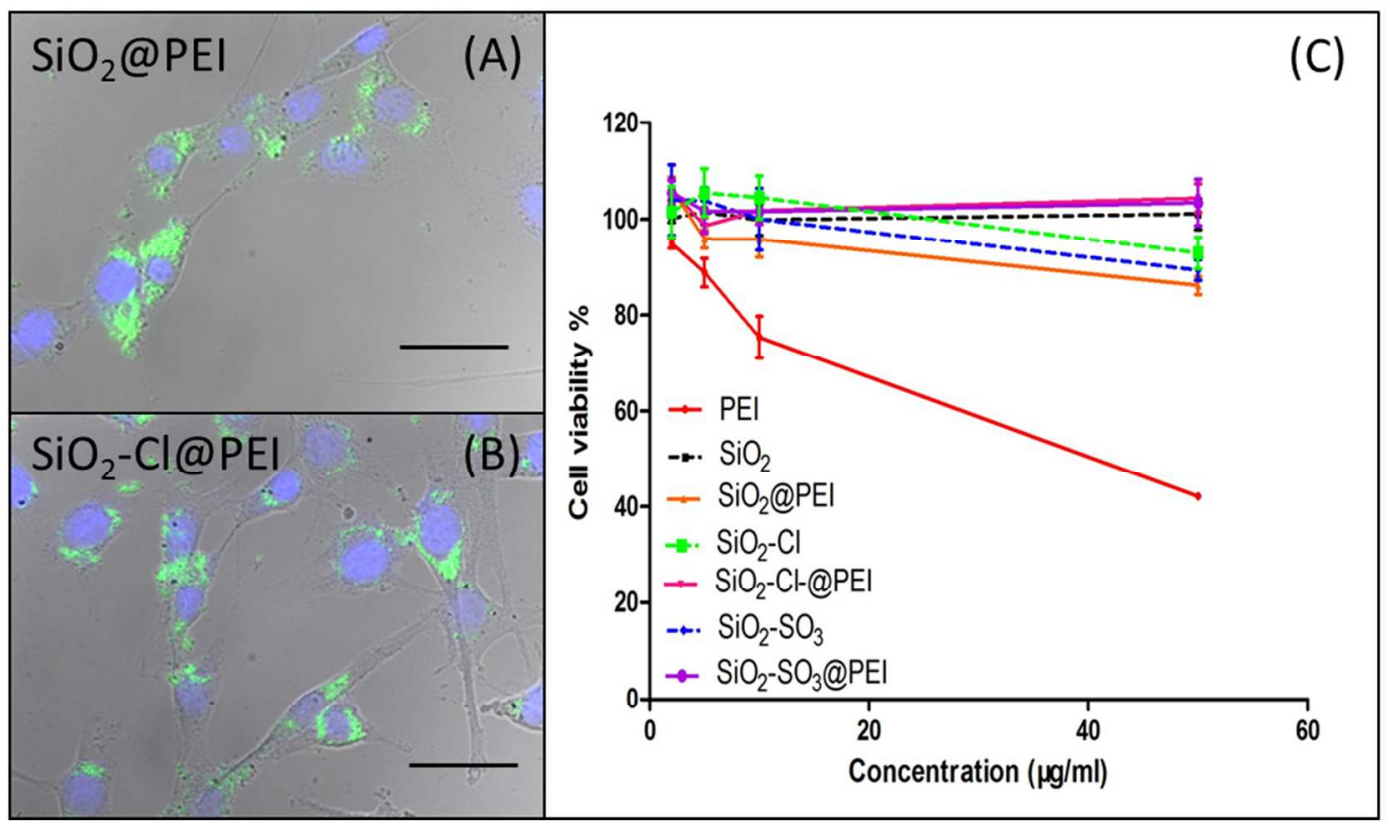

Figure 4: (A and B) Fluorescence microscopy image showing internalization of pGLuc:particle@PEI by $3 \mathrm{~T} 3$ fibroblasts after $48 \mathrm{~h}$ of incubation (green: FITC-labeled particles, blue : DAPI nuclei staining, scale bar $=20 \mu \mathrm{m})$; (C) Impact of PEI, particles and particle@PEI systems on $3 \mathrm{~T} 3$ cell viability after $4 \mathrm{~h}$ of contact as monitored by the Alamar Blue test. Bar: $50 \mu \mathrm{m}$.

The transfection efficiency of the particles was evaluated in 3T3 mouse fibroblasts and primary human keratinocytes using a plasmid encoding for Luciferase (pG-Luc) (Figure 5). Quantities of polymers used in this experiment were not toxic for cells with the aim of 
comparing the abilities of transfection of the different systems. The ability of transfection was first analyzed on immortalized 3T3 fibroblasts (Figure 5a). Among particles, the highest bioluminescence level was obtained with $\mathrm{SiO}_{2} @ \mathrm{PEI}$, that was one order of magnitude below that of PEI alone. ${ }^{25}$ The efficiency of $\mathrm{SiO}_{2}-\mathrm{SO}_{3} @$ PEI particles was ten times lower than that measured with $\mathrm{SiO}_{2} @$ PEI. Last, a very weak luciferase activity was observed with the $\mathrm{SiO}_{2}$-Cl@PEI system that was not statistically different from the control.

(A)

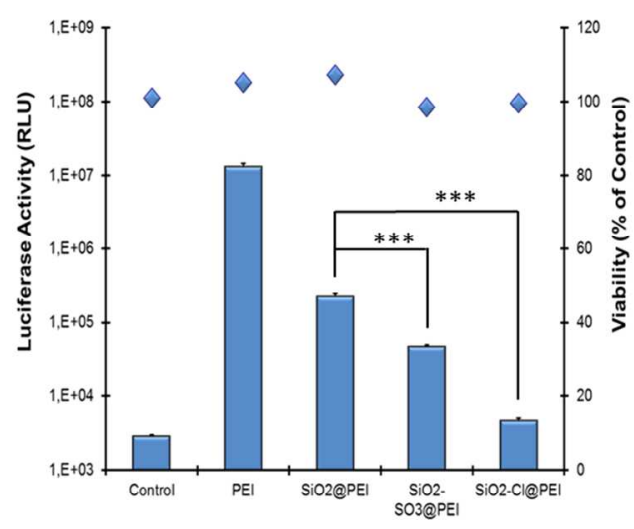

(B)

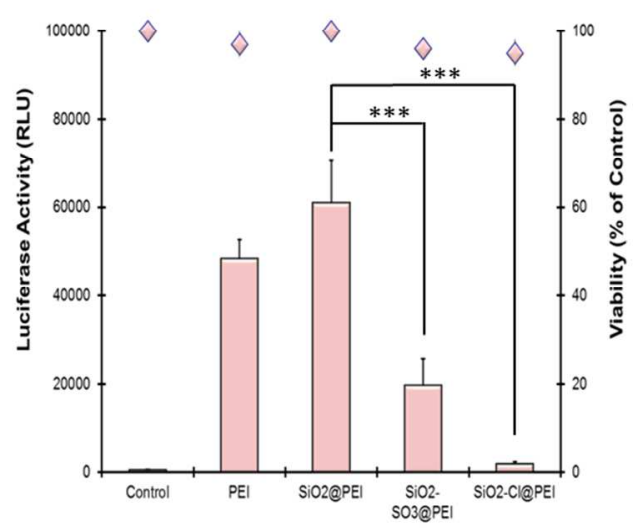

Figure 5: Transfection of mouse 3T3 fibroblasts (A) and human primary keratinocytes (B) after a 4 h incubation period with pGLuc :particle@PEI systems. Variance of the 
luciferase expression among particle groups was determined by one-way ANOVA with Tukey posthoc test $(* * * \mathrm{P}<0.001)$

Indeed, the luciferase activity was only the double of the basal level quantified in controls samples (without pG-Luc). The potential of PEI@particles to delivery genes was also investigated on primary normal human keratinocytes (Figure 5b). The bioluminescene levels measured after incubation with the different systems of particles revealed the same profiles of transfection as those observed in 3T3 cells. The best ability of transfection was obtained with $\mathrm{SiO}_{2} @$ PEI. The transfection efficiency was three times lower with $\mathrm{SiO}_{2}-\mathrm{SO}_{3} @$ PEI particles and that measured with the $\mathrm{SiO}_{2}-\mathrm{Cl} @$ PEI system was very low. Compared with the performance of the different particles@PEI systems on $3 \mathrm{~T} 3$ cells, the bioluminescence levels measured with keratinocytes were two times lower.

Despite their extensive study, the exact mechanisms driving cell transfection by non-viral vectors are still controversial. ${ }^{37}$ Yet the main steps of the process have been identified. First, the DNA complex must be internalized by endocytosis, a process that depends on its size and charge. Here, the three particles exhibit similar positive charges compatible with internalization. $\mathrm{SiO}_{2} @ \mathrm{PEI}$ and $\mathrm{Si}-\mathrm{SO}_{3} @ \mathrm{PEI}$ particles have similar dimensions (ca. $200 \mathrm{~nm}$ ) in PBS whereas $\mathrm{SiO}_{2}-\mathrm{Cl} @ \mathrm{PEI}$ dispersions show a tendency to aggregate into larger species $(\mathrm{ca} .800 \mathrm{~nm})$. Nevertheless fluorescence images suggest the successful internalization of a fraction of $\mathrm{SiO}_{2}-\mathrm{Cl} @$ PEI particles. This could be explained by the de-aggregation of $\mathrm{SiO}_{2}-\mathrm{Cl} @ \mathrm{PEI}$, allowing the uptake of individual particles. A 
second hypothesis relies on the polydispersity of $\mathrm{SiO}_{2}-\mathrm{Cl} @$ PEI particles. According to the results obtained by DLS, a small fraction of particles possesses the appropriate size (less than $400 \mathrm{~nm}$ ) to be engulfed by cells. Despite the fact that the uptake abilities are cell dependent, it is generally admitted that particles larger than $500 \mathrm{~nm}$ are not likely to be internalized by endocytosis in mammalian cells. ${ }^{19,38}$ This could explain the very low level of transfection. The question of the particle size, rather the covalent bonding seems to a crucial parameter for cellular uptake of $\mathrm{SiO}_{2}-\mathrm{Cl} @$ PEI. Several groups have functionalized PEI by covalent attachment on mesoporous silica nanoparticles or on hyaluronic acid chains. They obtained particles:DNA complexes with a limited aggregation (less than $350 \mathrm{~nm}$ ), thereby permitting cellular uptake and transfection. ${ }^{39-41}$ In addition, some of these particles were functionalized with mannose facilitating the engulfment by receptor-mediated endocytosis. ${ }^{40}$ Last, the studied cells were macrophages that are cells with high efficiency of engulfment.

In a second step, DNA must be released in the cytoplasm. ${ }^{37}$ This is possible via endosome acidification leading to endosomal membrane disruption. The plasmid carrier can play a role both in the destabilization of the endosome via the proton sponge effect and in the protection of DNA against acidic degradation. The first effect increases with the amount of PEI and should therefore be more favorable with $\mathrm{SiO}_{2}$. The protecting effect depends on the PEI quantity, its conformation and flexibility. ${ }^{10}$ The ratio PEI:DNA for $\mathrm{SiO}_{2} @ \mathrm{PEI}, \mathrm{Si}-\mathrm{SO}_{3} @ \mathrm{PEI}, \mathrm{SiO}_{2}-\mathrm{Cl} @ \mathrm{PEI}$ were 3.8, 1.2 and 1.7, respectively. According to the results of cell viability, these ratios were not associated with any 
cytotoxicity. It is well-admitted that the transfection capabilities increase when the PEI:DNA ratio rises. ${ }^{42}$ Hence, the quantity of PEI on $\mathrm{SiO}_{2}$ particles could explain in part its higher transfection ability because of its impact on DNA compaction and protection against nucleases. Nevertheless, the conformation of PEI at the surface also plays an important role and is expected to be optimal for the $\mathrm{Si}_{-} \mathrm{SO}_{3} @ \mathrm{PEI}$ system.

In a following step, the released plasmid must diffuse to the nucleus and enter, either during mitosis or via the nuclear import machinery. Importantly, the stage at which PEI and DNA are dissociated is still a matter of debate. ${ }^{37}$ However, focusing on the particle-PEI interactions, it is interesting to note that in the acidic conditions of the endosomes, an important fraction of the silanolate groups of the bare silica particles become protonated. This decreases the negative charge of the carrier, favoring PEI desorption. On the opposite, sulfonate functions should remain negatively-charged, preserving their attractive interactions with PEI. Finally, for $\mathrm{SiO}_{2}-\mathrm{Cl}$, the existing covalent bonds are not expected to be cleaved, limiting the possibility for complexes to escape. These trends in PEI detachment from particles nicely follow the measured transfection efficiencies, suggesting that such a release is a relevant event in the plasmid delivery process.

Surprisingly, the performance of PEI alone was not better than that of the $\mathrm{SiO}_{2} @$ PEI system for keratinocytes, in contrast to the results obtained with 3T3 cells. The highest cell transfection observed with PEI compared to particles on immortalized cells could be explained by the particle size and the metabolic activity of 3T3 fibroblasts. 
PEI/DNA complexes are about $100 \mathrm{~nm}$ in diameter. ${ }^{43}$ These complexes are rapidly uptaken by cells via the chlatrin-mediated endocytosis. In contrast, larger particles@PEI systems are more internalized by the caveolin-mediated endocytosis. ${ }^{44}$ Therefore the chlatrin pathway seems to be more efficient in $3 \mathrm{~T} 3$ fibroblasts to engulf complexes. Second, 3T3 cells proliferate rapidly, facilitating plasmid transfer by disruption of the nuclear membrane during cell division. Thus it can be proposed that PEI complexes are rapidly uptaken, transported to the nucleus and that protein expression occurs at a very high rate thanks to fast proliferation. In contrast, the uptake of particles being less efficient, there is a delay required for sufficient plasmid accumulation before significant protein expression is achieved. In the case of primary cells such as keratinocytes, the cells proliferate at a lower rate. Therefore the overall protein expression rate is slower for both systems. Moreover, in these conditions, it is possible for silica particles to accumulate in a higher quantity between two cellular division event, so that the protein expression level becomes comparable to that of PEI.

\section{CONCLUSION}

These results provide an important insight on the relationship between the chemistry of silica nanoparticles and their biological properties as gene delivery vectors. Whereas great attention has already been paid to the optimization of the plasmid loading, we have here enlightened the influence of the chemistry of the particle surface on the conformation and lability of the cationic coating. Such effects were observed for both immortalized and 
primary mammalian cells. Our findings particularly suggest that a delicate balance has to be established between weak particle/coating and strong coating/plasmid interactions. They therefore provide interesting guidelines for further optimization of nanoparticle-based gene carriers but also, on a more general level, for the design of nanovectors for intracellular delivery of bioactive molecules.

\author{
ASSOCIATED CONTENT \\ Supporting Information. TEM images (Figure S1), ${ }^{13} \mathrm{C}$ IRCP-MAS spectra (Figure \\ S2), full XPS spectra (Figure S3). This material is available free of charge via the \\ Internet at http://pubs.acs.org.
}

\author{
AUTHOR INFORMATION \\ Corresponding Authors. *Email: thibaud.coradin@upme.fr; \\ christophe.helary@upmc.fr
}

\title{
ACKNOWLEDGMENTS
}

X.W. PhD grant was funded by the China Scholarship Council. The authors thank C. Aimé (LCMCP) for fruitful discussions and C. Méthivier (UPMC) for the XPS experiments. 


\section{REFERENCES}

(1) Cartier, N.; Hacein-Bey-Abina, S.; Bartholomae, C.C.; Veres, G.;Schmidt, M.; Kutschera, I.; Vidaud, M.; Abel, U.; Dal-Cortivo, L.; Caccavelli, L.; Mahlaoui, N.; Kiermer, V.; ittelstaedt, D.;Bellesme, C.; Lahlou, N.; Lefrere, F.; Blanche, S.; Audit, M.;Payen, E.; Leboulch, P.; l'Homme, B.; Bougneres, P.; Von Kalle, C.; Fischer, A.; Cavazzana-Calvo, M.; Aubourg, P. Hematopoieticstem cell gene therapy with a lentiviral vector in X-linked adrenoleukodystrophy. Science, 2009, 326, 818-823.

(2) Kay, M. A.; Manno, C. S.; Ragni, M. V.; Larson, P. J.; Couto, L. B.;McClelland, A.; Glader, B.; Chew, A. J.; Tai, S. J.; Herzog, R. W.; Arruda, V.; Johnson, F.; Scallan, C.; Skarsgard, E.; Flake, A.W.; High, K. A. Evidence for gene transfer and expression of factor IXin haemophilia B patients treated with an AAV vector. Nature Genetics, 2000, $24,257-261$.

(3) De Laporte, L.; Huang, A.; Ducommun, M. M.; Zelivyanska, M. L.; Aviles, M. O.; Adler, A. F.; Shea, L. D. Patterned transgene expression in multiple-channel bridges after spinal cord injury. Acta Biomater., 2010, 6, 2889-2897.

(4) Kofron, M.D.; Laurencin, C. T. Bone tissue engineering by gene delivery. Adv. Drug Deliv. Rev., 2006, 58, 555-576.

(5) Zhang, Y.; Wang, Z.; Gemeinhart, R. A. Progress in microRNA delivery. J Control. Release, 2013, 172, 962-974. 
(6) Bonadio, J.; Smiley, E.; Patil, P.; Goldstein, S. Localized, direct plasmid gene delivery in vivo: prolonged therapy results in reproducible tissue régénération. Nat. Med. 1999, 5, 753-759.

(7) Davidson, B. L.; McCray, P. B., Jr. Current prospects for RNA interference-based therapies. Nat. Rev. Genetics 2011, 12, 329-340

(8) Seidlits, S. K.; Gower, R. M.; Shepard, J. A.; Shea, L. D. Hydrogels for lentiviral gene delivery. Expert Opin Drug Deliv. 2013, 10, 499-509.

(9) Aied, A.; Greiser, U.; Pandit, A.; Wang, W. Polymer gene delivery: overcoming the obstacles. Drug Discov. Today, 2013, 18, 1090-1098.

(10) Godbey, W. T.; Wu, K. K.; Mikos, A. G. Poly(ethylenimine) and Its Role in Gene Delivery. J. Controlled Release 1999, 60, 149-160.

(11)Patnaik, S.; Gupta, K. C. Novel polyethylenimine-derived nanoparticles for in vivo gene delivery. Expert Opin. Drug Del. 2013, 10, 215-228.

(12) Guo, X.; Huang, L. Recent Advances in Nonviral Vectors for Gene Delivery. Acc. Chem. Res. 2012, 45, 971-979.

(13)Hartono, S. B.; Gu, W.; Kleitz, F.; Liu, J.; He, L.; Middelberg, A. P. J.; Yu, C.; Lu, G. Q.; Qiao, S. Z. Poly-1-lysine Functionalized Large Pore Cubic Mesostructured Silica Nanoparticles as Biocompatible Carriers for Gene Delivery. ACS Nano 2012, 6, 2104-2117. 
(14)Fuller, J. E.; Zugates, G. T.; Ferreira, L. S.; Ow, H. S.; Nguyen, N. N.; Wiesner, U. B.; Langer, R. S. Intracellular delivery of core-shell fluorescent silica nanoparticles. Biomaterials 2008, 29, 1526-1532.

(15) Luo, D.; Saltzman, W. M. Enhancement of transfection by physical concentration of DNA at the cell surface. Nat. Biotech. 2000, 18, 893-895.

(16) He, L.; Feng, L.; Cheng, L.; Liu, Y.; Li, Z.; Peng, R.; Li, Y.; Guo, L.; Liu, Z. Multilayer dual-polymer-coated upconversion nanoparticles for multimodal imaging and serum-enhanced gene delivery. ACS Appl. Mater. Interfaces 2013, 5, 10381-10388.

(17) Mamaeva, V.; Sahlgren, C.; Lindén, M. Mesoporous silica nanoparticles in medicine-Recent advances. Adv. Drug Del. Rev. 2013, 65, 689-702.

(18) Tang, F.; Li, L.; Chen, D. Mesoporous Silica Nanoparticles: Synthesis, Biocompatibility and Drug Delivery. Adv. Mater. 2012, 24, 1504-1534.

(19) Mao, Z.; Zhou, X. ; Gao, C. Influence of structure and properties of colloidal biomaterials on cellular uptake and cell functions. Biomater. Sci. 2013, 1, 896-911.

(20) Lay, C.-Y.; Trewyn, B. G.; Jeftinija, D. M.; Xu, S.; Jeftinija, S.; Lin, V. S. Mesoporous Silica Nanosphere-Based Carrier System with Chemically Removable CdS Nanoparticle Caps for Stimuli-Responsive Controlled Release of Neurotransmitters and Drug Molecules. J. Am. Chem. Soc. 2003, 125, 4451-4459.

(21)Kecht, J.; Schlossbauer, A.; Bein, T. Selective Functionalization of the Outer and Inner Surfaces in Mesoporous Silica Nanoparticles. Chem. Mater. 2008, 20, 7207-7214. 
(22) Xia, T.; Kovochich, M.; Liong, M.; Meng, H.; Kabehie, S.; George, S.; Zink, J. I.;

Nel, A. E. Polyethyleneimine Coating Enhances the Cellular Uptake of Mesoporous Silica Nanoparticles and Allows Safe Delivery of siRNA and DNA Constructs. ACS Nano 2009, 3, 3273-3286.

(23) Yu, M.; Niu, Y.; Yang, Y.; Hartono, S. B.; Yang, J.; Huang, X.; Thorn, P.; Yu, C. An Approach to Prepare Polyethylenimine Functionalized Silica-Based Spheres with Small Size for siRNA Delivery. ACS Appl. Mater \& Inter. 2014, 6, 15626-15631.

(24) Stöber, W.; Fink, A.; Bohn, E. Controlled growth of monodisperse silica spheres in the micron size range. J. Colloid Interface Sci. 1968, 26, 62-69.

(25) Wang, X.; Helary, C.; Coradin, T. Local and Sustained Gene Delivery in Silica-Collagen Nanocomposites. ACS Appl. Mater \& Inter. 2015, 7, 2503-2511

(26) Aimé, C.; Mosser, G.; Pembouong, G.; Bouteiller, L.; Coradin, T. Controlling the nano-bio interface to build collagen-silica self-assembled networks. Nanoscale 2012, 4, 7127-7134.

(27) Ellman G.L . Tissue sulfhydryl groups. Arch. Biochem. Biophys. 1959, 82, 70-73

(28) Quignard, S.; Mosser, G.; Boissière, M.; Coradin, T. Long-term fate of silica nanoparticles interacting with human dermal fibroblasts. Biomaterials 2012, 33, 4431-4442

(29) Louette, P.; Bodino, F.; PIreaux, J.-J. Poly-ethylene imine (PEI) XPS Reference Core Level and Energy Loss Spectra. Surface Sci. Spectra, 2005, 12, 54-58

(30) Shchukarev, A.; Rosenqvist, J.; Sjöberg, S. XPS study of the silica-water interface. 
J. Electron Spectr. Related Phenom. 2004, 137-140, 171-176

(31) Islam, Md. S.; Choi, W. S.; Lee, H.-J. Controlled Etching of Internal and External Structures of $\mathrm{SiO}_{2}$ Nanoparticles Using Hydrogen Bond of Polyelectrolyte. ACS Appl. Mater. Interfaces 2014, 6, 9563-9571

(32) Nasef, N. N.; Saidi, H.; Nor, H. M.; Yarmo, M. A. XPS Studies of Radiation Grafted PTFE-g-polystyrene Sulfonic Acid Membranes. J. Appl. Polym. Sci. 2000, 76, 336-349

(33) Tsiourvas, D.; Tsetsekou, A.; Arkas, M.; Diplas, S.; Mastrogianni, E. Covalent attachment of a bioactive hyperbranched polymeric layer to titanium surface for the biomimetic growth of calcium phosphates. J. Mater. Sci. Mater. Med. 2011, 22, 85-96.

(34) Nagaya, J.; Homma, M.; Tanioka, A.; Minakata, A. Relationship between protonation and ion condensation for branched poly(ethylenimine). Biophys. Chem. 1996, $60,45-51$.

(35)Leung, K.; Nielsen, I. M. B.; Criscenti, L. J. Elucidating the Bimodal Acid-Base Behavior of the Water-Silica Interface from First Principles. J. Am. Chem. Soc. 2009, $131,18358-18365$.

(36) Wightman, L.; Kircheis, R.; Rossler, V.; Carotta, S.; Ruzicka, R.; Kursa, M.; Wagner, E. Different Behavior of Branched and Linear Polyethylenimine for Gene Delivery In vitro and In vivo. J. Gene Med. 2001, 3, 362-372.

(37)Won, Y.-Y.; Sharma, R.; Konieczny, S. F. Missing pieces in understanding the intracellular trafficking of polycation/DNA complexes. J. Controlled Release 2009, 139, $88-93$. 
(38) Wang, Z. J.; Tiruppathi, C.; Minshall, R. D; Malik, A., B. Size and dynamics of caveolae studied using nanoparticles in living endothelial cells. ACS Nano. 2009, 3, 4110-4116.

(39) Buchman, Y. K.; Lellouche, E.; Zigdon, S.; Bechor, M.; Michaeli, S.; Lellouche, J.-P. Silica Nanoparticles and Polyethyleneimine (PEI)-Mediated Functionalization: A New Method of PEI Covalent Attachment for siRNA Delivery Applications. Bioconjugate Chem. 2013, 24, 2076-2087.

(40) Park, I. Y.; Kim, I. Y.; Yoo, M. K.; Choi, Y. J. ; Cho, M. H. ; Cho, C. S. Mannosylated polyethylenimine coupled mesoporous silica nanoparticles for receptor-mediated gene delivery. Int. J. Pharm. 2008, 359, 280-287.

(41) Jiang, G.; Park, K.; Kim, J.; Oh, E. J.; Kang, H.; Han, S.-E.; Oh Y.-K; Park, T. G; Hahn, S., K. Hyaluronic acid-polyethyleneimine conjugate for target specific intracellular delivery of siRNA. Biopolymers 2008, 89, 635-642.

(42) Huang, Y. C. ; Connell, M. ; Park, Y. ; Mooney, D. J. ; Rice, K. G. Fabrication and in vitro testing of polymeric delivery system for condensed DNA. J. Biomed Mater. Res. A. 2003, 67, 1384-1392.

(43) Fischer, D.; Bieber, T.; Li, Y. X.; , Elsasser, H. P.; Kissel, T. A novel non-viral vector for DNA delivery based on low molecular weight, branched polyethylenimine: Effect of molecular weight on transfection efficiency and cytotoxicity. Pharmaceut Res. 1999, 16, 1273-9. 
(44) Rejman, J.; Oberle, V.; Zuhorn, I. S.; Hoekstra, D. Size-dependent Internalization of Particles via the Pathways of Clathrin- and Caveolae-mediated Endocytosis. Biochem. J. 2004, 377, 159-169.

1

2

4

5

6

7

10

11

12

13

14

15

16

17

18

19

20

21

22

23

24

25

26

27

28

29

30

31

32

33

34

35

36

37

38

39

40

41

42

43

44

45

46

47

48

49

50

51

52

53

54

55

56

57

58

59

60 


\section{TOC graphics}

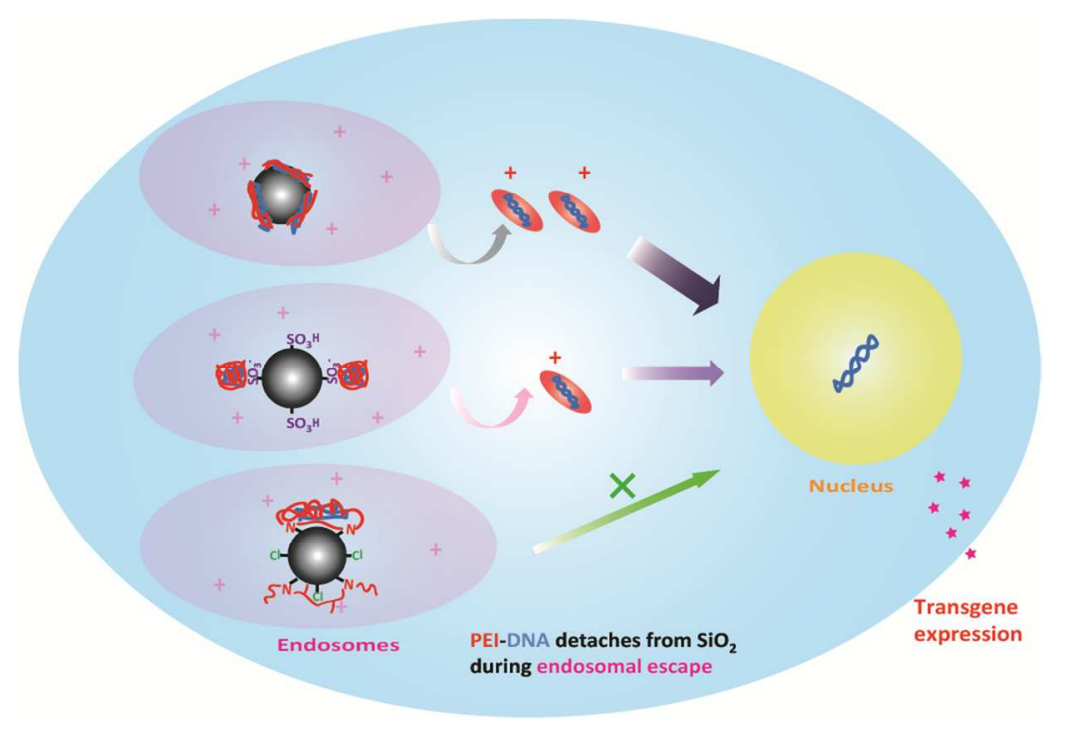




\section{Impact of Polyethyleneimine Conjugation Mode on the Cell Transfection Efficiency of Silica Nanovectors}

Xiaolin Wang, Sylvie Masse, Guillaume Laurent, Christophe Hélary,* and Thibaud Coradin*

Sorbonne Universités, UPMC Univ Paris 06, CNRS, UMR 7574, Laboratoire de Chimie de la Matière Condensée de Paris, F-75005 Paris, France

*Corresponding Author: Email: thibaud.coradin@upmc.fr

\section{Supporting Information}

S1. Detailed experimental protocols

Figure S1. TEM images of nanoparticles

Figure S2. XPS spectra of nanoparticles

Figure S3. Agarose gel electrophoresis

Figure S4. ${ }^{13} \mathrm{C}$ IRCP-MAS NMR spectra

Figure S5. Cell viability at the end of transfection experiments 


\section{S1. Detailed experimental protocols}

Silica-polyethyleneimine particle preparation. Silica nanoparticles $\mathrm{SiO}_{2}$ were synthesized by Stöber method using ammonia for the hydrolysis and polymerization of tetraethylorthosilicate (TEOS, Sigma). The amount of chemicals was shown in the table below.

\begin{tabular}{|c|c|c|c|}
\hline TEOS $(\mathrm{mL})$ & Ethanol $(\mathrm{mL})$ & $\mathrm{H}_{2} \mathrm{O}(\mathrm{mL})$ & Ammonia $(25 \%, \mathrm{~mL})$ \\
\hline 7.6 & 200 & 5.9 & 9.7 \\
\hline
\end{tabular}

For $\mathrm{SiO}_{2} @$ PEI particle preparation, 200 mg of branched polyethyleneimine PEI (25 $\mathrm{kDa}$ ) was dissolved in $20 \mathrm{~mL}$ of saline phosphate buffer (PBS, $10 \mathrm{mM}, \mathrm{pH} 7.4$ ). Silica nanoparticle suspension in PBS $(20 \mathrm{ml})$ was then added dropwise into the PEI solution under stirring. The mixtures were stirred for $48 \mathrm{~h}$ and particles were recovered by centrifugation, washed 3 times in PBS and finally resuspended in PBS.

For $\mathrm{SiO}_{2}-\mathrm{SO}_{3} @$ PEI particle preparation, the SiNP was first functionalized with thiol groups by silylation with 3-mercaptopropyltrimethoxysilane (MPTMS). Typically, $1 \mathrm{~g}$ of silica was dispersed in a mixture of $100 \mathrm{ml}$ ethanol and $2.2 \mathrm{ml}$ ammonium hydroxide solution before addition of $1 \mathrm{ml} \mathrm{MPTMS}$. The mixture was stirred for $40 \mathrm{~min}$ at room temperature. Subsequently, the reaction mixture was heated to $80{ }^{\circ} \mathrm{C}$ and the total volume was reduced by $2 / 3$ by distillation of ethanol and ammonia at ambient pressure. Then, the mixture was cooled back to room temperature, centrifuged, washed 3 times with ethanol and dried at $60{ }^{\circ} \mathrm{C}$. Then $0.9 \mathrm{~g}$ of the thus-obtained $\mathrm{SiO} 2-\mathrm{SH}$ was suspended in $45 \mathrm{~mL}$ 
hydrogen peroxide $\left(\mathrm{H}_{2} \mathrm{O}_{2} 35 \%\right.$, Acros Organics) under stirring at RT for 48 hours. The solid product was washed by centrifugation with distilled water before addition of $35 \mathrm{~mL}$ of concentrated sulfuric acid $\left(\mathrm{H}_{2} \mathrm{SO}_{4} 95.0-98.0 \%\right.$, Sigma Aldrich) and stirred for 2 hours at RT. Finally the as-synthesized $\mathrm{SiO}_{2}-\mathrm{SO}_{3}$ particles were washed with water, suspended in PBS and coated with PEI as described above.

For $\mathrm{SiO}_{2}-\mathrm{Cl} @$ PEI particle preparation, 400 mg of $\mathrm{SiO}_{2}$ nanoparticles was dispersed in $20 \mathrm{~mL}$ of dried toluene, and $1.3 \mathrm{~mL}$ of chloropropyltriethoxysilane (Cl-PTES) was added to the suspension, that was further kept under reflux for $24 \mathrm{~h}$. The product was washed thoroughly with toluene and ethanol, and dried at room temperature. Then, 200 $\mathrm{mg} \mathrm{SiO} \mathrm{S}_{2}-\mathrm{Cl}$ was dispersed in $20 \mathrm{ml}$ ethanol, and $0.8 \mathrm{~g}$ of PEI was added to the suspension. The suspension was refluxed for $24 \mathrm{~h}$. The final solid product was recovered by washing with ethanol and dried at room temperature. The as-synthesized SiNP-Cl@PEI was suspended in $10 \mathrm{mM}$ PBS (pH 7.4) before use.

Characterizations of $\mathrm{SiO}_{2}$-X@PEI Particle. Sizes and zeta potential $(\zeta)$ were measured in $10 \mathrm{mM}$ PBS solution using a ZetaSizer Nano (Malvern Instruments Ltd., Worcestershire, UK). Particles were also imaged using Transmission Electron Microscopy (TEM) on a JEOL 1011 instrument. The amount of adsorbed PEI was determined by elemental analysis $(\mathrm{C}, \mathrm{H}, \mathrm{O}, \mathrm{N})$. Specially, for $\mathrm{SiO}_{2}-\mathrm{SO}_{3}$, the amount of $\mathrm{SO}_{3}$ was calculated according to the amout of $-\mathrm{SH}$ before oxidation, which is determined by Ellman test. For this test, a phosphate buffer $(0.2 \mathrm{M}, \mathrm{pH}=7.3)$ was prepared and labeled as solution A. Solution B (10 mM EDTA) was produced by dissolving $372 \mathrm{mg}$ of EDTA 
in $100 \mathrm{~mL}$ of solution $\mathrm{A}$, and solution $\mathrm{C}(6 \mathrm{mM} \mathrm{DTNB})$ was prepared by dissolving 238 $\mathrm{mg}$ of DTNB in $100 \mathrm{~mL}$ of solution A. Several vials were filled with a mixture of $8 \mathrm{ml}$ of solution $\mathrm{A}, 1 \mathrm{~mL}$ of solution $\mathrm{B}$ and $1 \mathrm{~mL}$ of solution C. A series of masses of $\mathrm{SiO}_{2}-\mathrm{SH}$, less than $50 \mathrm{mg}$, were measured and then each dispersed into a vial mixture solution. Simultaneously, several known quantities of thiol (obtained from a solution of MPTMS) were also introduced in the same mixture solution to determine the molar extinction coefficient by linear regression. After 45 minutes of stirring, the particle dispersion is filtered through a syringe filter. The absorbance of the filtrate and standard MPTMS solutions are determined by spectroscopy. The absorbance of the solutions MTPMS can be traced back to the value for the experience of the molar extinction coefficient of NTB $^{2-}$ by linear regression. It can then inform the thiol concentration, therefore sulfonates, on the surface of our particles.

pDNA-PEI and pDNA-SiO2-X@PEI Complexation. Reporter plasmid pCMV-GLuc (pGluc) encoding Gaussia Luciferase (New England BioLabs, Ipswich, MA) was used to quantify transgene expression. This plasmid was amplified by one shot $^{\circledR}$ BL21(DE3) pLysS kit (Invitrogen ${ }^{\mathrm{TM}}$, Life technologies), extracted by one PureLink ${ }^{\circledR}$ HiPure Plasmid kit (Invitrogen ${ }^{\mathrm{TM}}$, Life technologies) and finally stored in Tris-EDTA buffer at $-20{ }^{\circ} \mathrm{C}$. pDNA-PEI complexes were prepared at weight ratio of 1:2. pDNA-SiO 2 -X@PEI $\left(\mathrm{X}=\right.$ none, $\left.\mathrm{SO}_{3}, \mathrm{Cl}\right)$ complexes were prepared at various pDNA: SiO2-X@PEI weight ratios. Complexes formation was examined by agarose gel 
electrophoresis. Briefly, $1 \mu \mathrm{L}$ of pDNA solution $\left(0.1 \mu \mathrm{g} . \mu \mathrm{L}^{-1}\right)$ were mixed homogeneously with a total volume of $9 \mu \mathrm{L}$ of $\mathrm{SiO} 2-\mathrm{X} @ \mathrm{PEI}$ suspension or PEI solution (PBS 1x) by vortexing in a microcentrifuge tube. The resulting mixtures were left at room temperature for $2 \mathrm{~h}$ to achieve complete complexation, before being loaded onto $0.7 \%$ agarose gel with ethidium bromide $\left(0.1 \mu \mathrm{g} \cdot \mathrm{mL}^{-1}\right)$ and running with TAE buffer at $100 \mathrm{~V}$ for $40 \mathrm{~min}$. DNA retardation was observed by irradiation with ultraviolet light.

Cell Transfection and Cell Viability. 3T3 mouse fibroblasts were cultured in complete cell culture medium (Dulbecco's Modified Eagle's Medium (DMEM) supplemented with $10 \%$ fetal serum, $100 \mathrm{U} \cdot \mathrm{mL}^{-1}$ penicillin, $100 \mu \mathrm{g} \cdot \mathrm{mL}^{-1}$ streptomycin and $0.25 \mu \mathrm{g} . \mathrm{mL}^{-1}$ Fungizone). Tissue culture flasks $\left(75 \mathrm{~cm}^{2}\right)$ were kept at $37^{\circ} \mathrm{C}$ in a $95 \%$ air: $5 \% \mathrm{CO}_{2}$ atmosphere. Before confluence, fibroblasts were removed from culture flasks by treatment with $0.1 \%$ trypsin and $0.02 \%$ EDTA. Cells were rinsed and resuspended in the above culture medium before use.

Transfection efficiency of pDNA-PEI and pDNA-SiO2-X@PEI were evaluated by luciferase expression of pGLuc by $3 \mathrm{~T} 3$ mouse fibroblast cells in cell culture medium. The cells were plated at a density of $5.10^{4}$ per well in a 24 -well plate. pDNA-PEI or pDNA-PEI-SiO2-X complexes $(25 \mu \mathrm{L})$ were added to the cell culture medium. After $4 \mathrm{~h}$, the supernatant was removed, the well was refreshed with $1 \mathrm{~mL}$ complete medium and the cells were then cultured for another $44 \mathrm{~h}$ for the expression of luciferase. For measurements of luciferase activity, a BioLux Gaussia Luciferase Assay Kit (New England Biolabs) was used and transgene expression of luciferase was reported as 
relative light units (RLU). Control groups were under the same culture condition as the experiment groups except for the absence of DNA complexes.

Internalization of nanoparticles in 3T3 mouse fibroblasts was studied using fluorescence microscopy. Fluorescent particles were obtained following the previously described protocol except for the addition of a solution of fluorescein-grafted aminopropyl triethoxysilane (APTES, Merck; FITC isomer 1 95\%, Alpha Aesar ). The pDNA-particle complexes were incubated with cells for $24 \mathrm{~h}$. The cell culture medium was removed and the cells were rinsed 3 times with PBS and fixed with 4\% paraformaldehyde for 1 hour at RT. The cell nucleus was then stained with DAPI (4',6-diamidino-2-phenylindole dihydrochloride, Life technologies, $300 \mathrm{nM}$ in PBS) for 10 min and rinsed with PBS before observation.

Cell viability was monitored using the Alamar Blue test as a function of particle dose after $4 \mathrm{~h}$ of contact and after transfection. In all cases, $200 \mu \mathrm{L}$ of the Alamar Blue solution ( $10 \%$ in cell culture medium) was added to $1 \mathrm{~mL}$ of the cell culture medium. The cells were then incubated at $37{ }^{\circ} \mathrm{C}$ with $5 \% \mathrm{CO}_{2}$ for $4 \mathrm{~h}$. The supernatant in each well was then collected, diluted with $800 \mu \mathrm{L}$ water, and its absorbance was measured at $\lambda=$ $570 \mathrm{~nm}$ and $600 \mathrm{~nm}$. Cell viability was calculated and reported as a percentage of the control group $(\mathrm{n}=6)$. 
Figure S1. TEM images of $\mathrm{SiO}_{2}, \mathrm{SiO}_{2}-\mathrm{SO}_{3}, \mathrm{SiO}_{2}$-Cl before(A-C) and after (D-F) modification with PEI $25 \mathrm{kDa}$

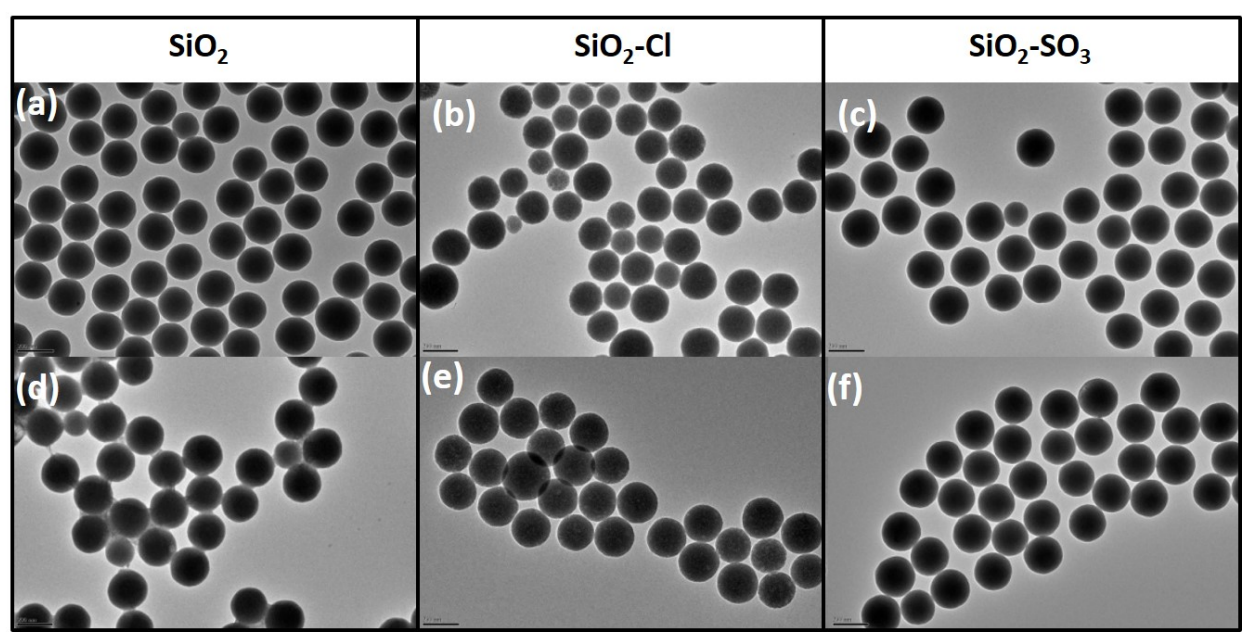


Figure S2. XPS spectra for $\mathrm{SiO}_{2}, \mathrm{SiO}_{2}-\mathrm{SO}_{3}, \mathrm{SiO}_{2}-\mathrm{Cl}$ before and after modification with PEI $25 \mathrm{kDa}$. PEI $25 \mathrm{kDa}$ was used for comparison

$\underset{\substack{\text { surveg } \\ \text { PEI }}}{\text { Pan }}$
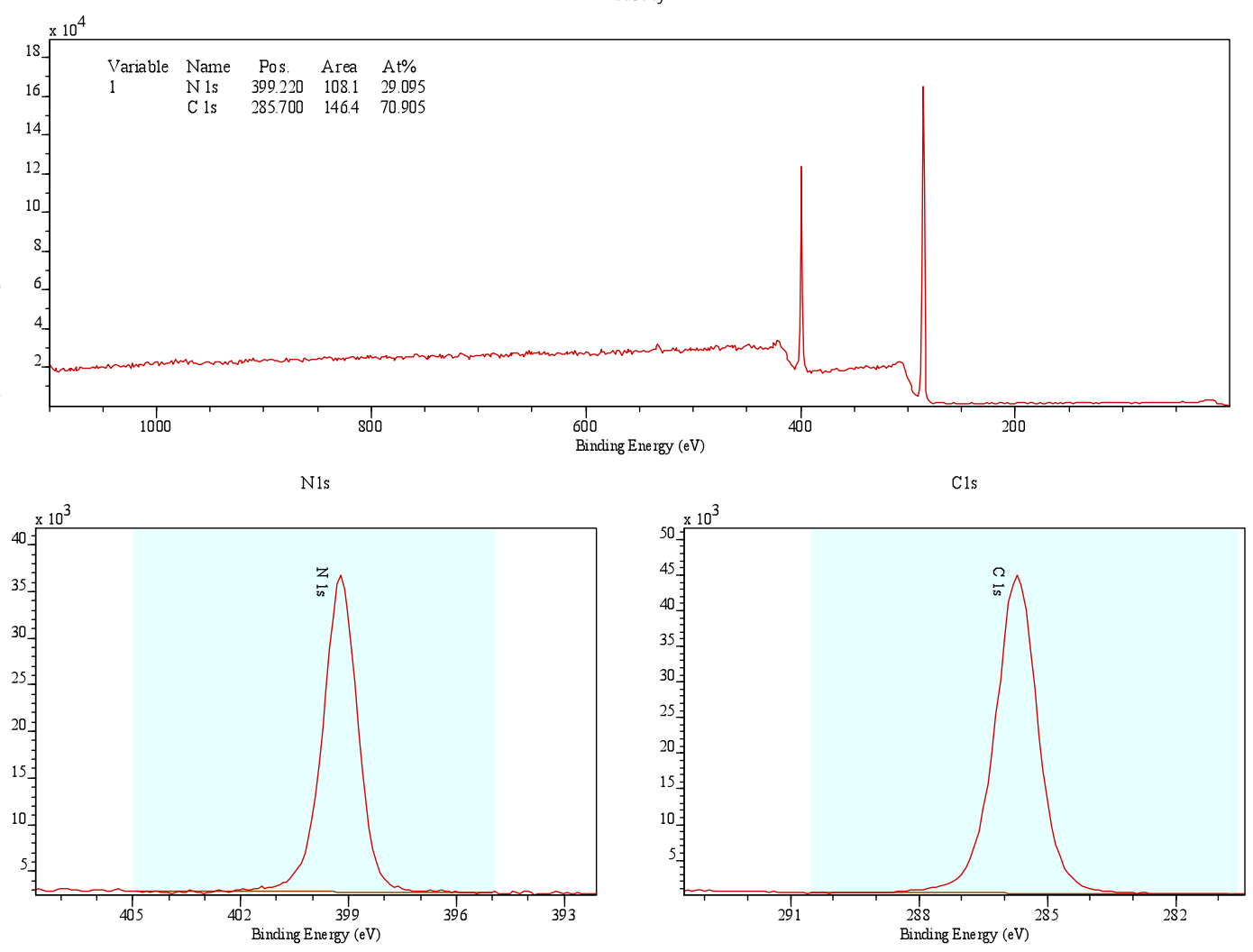
$\mathrm{SiO}_{2}$
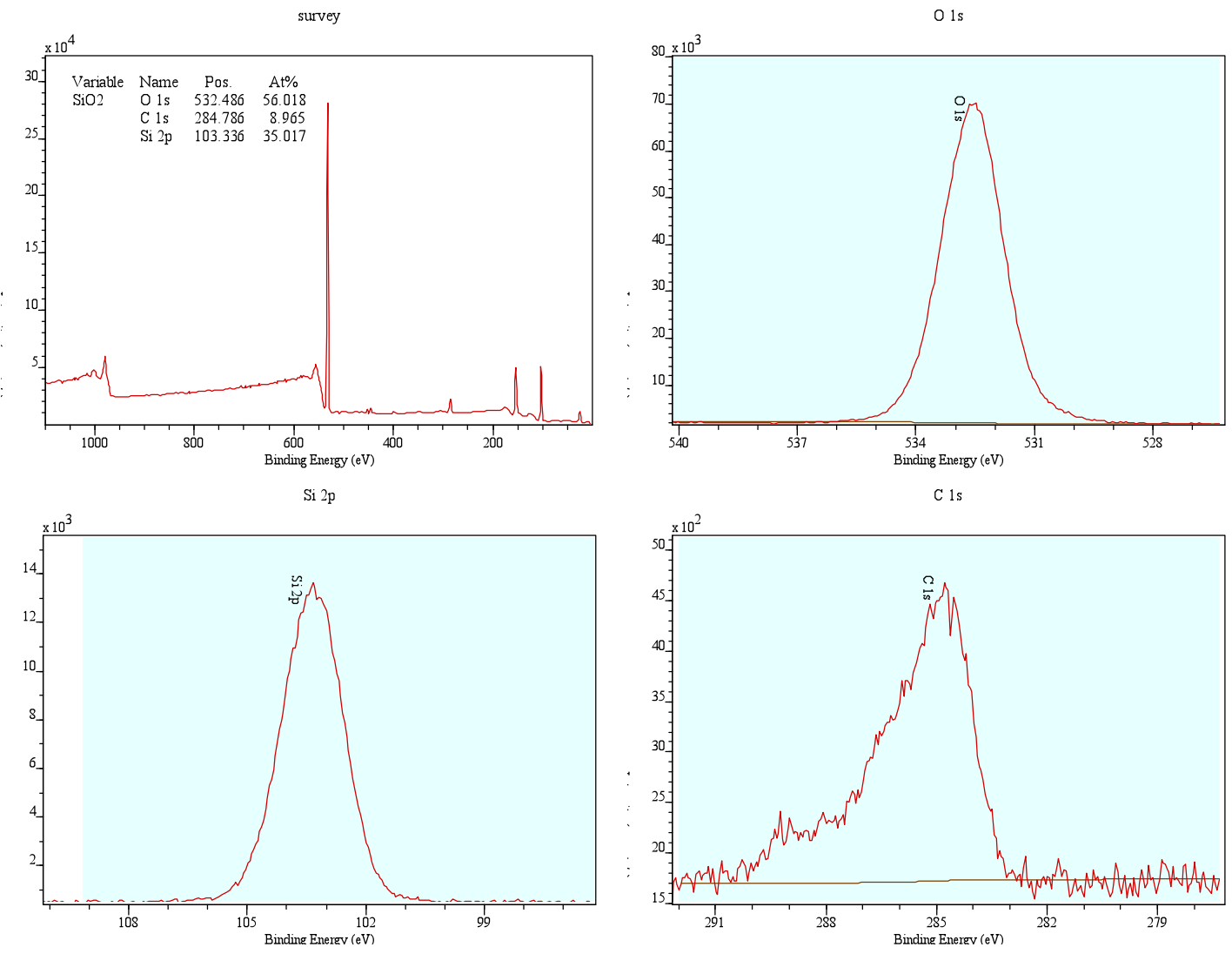

CasaXPS (This string can be edited in CasaXPS.DEF/PrintFootNote.txt) 


\section{SiO $@ @ P E I$}
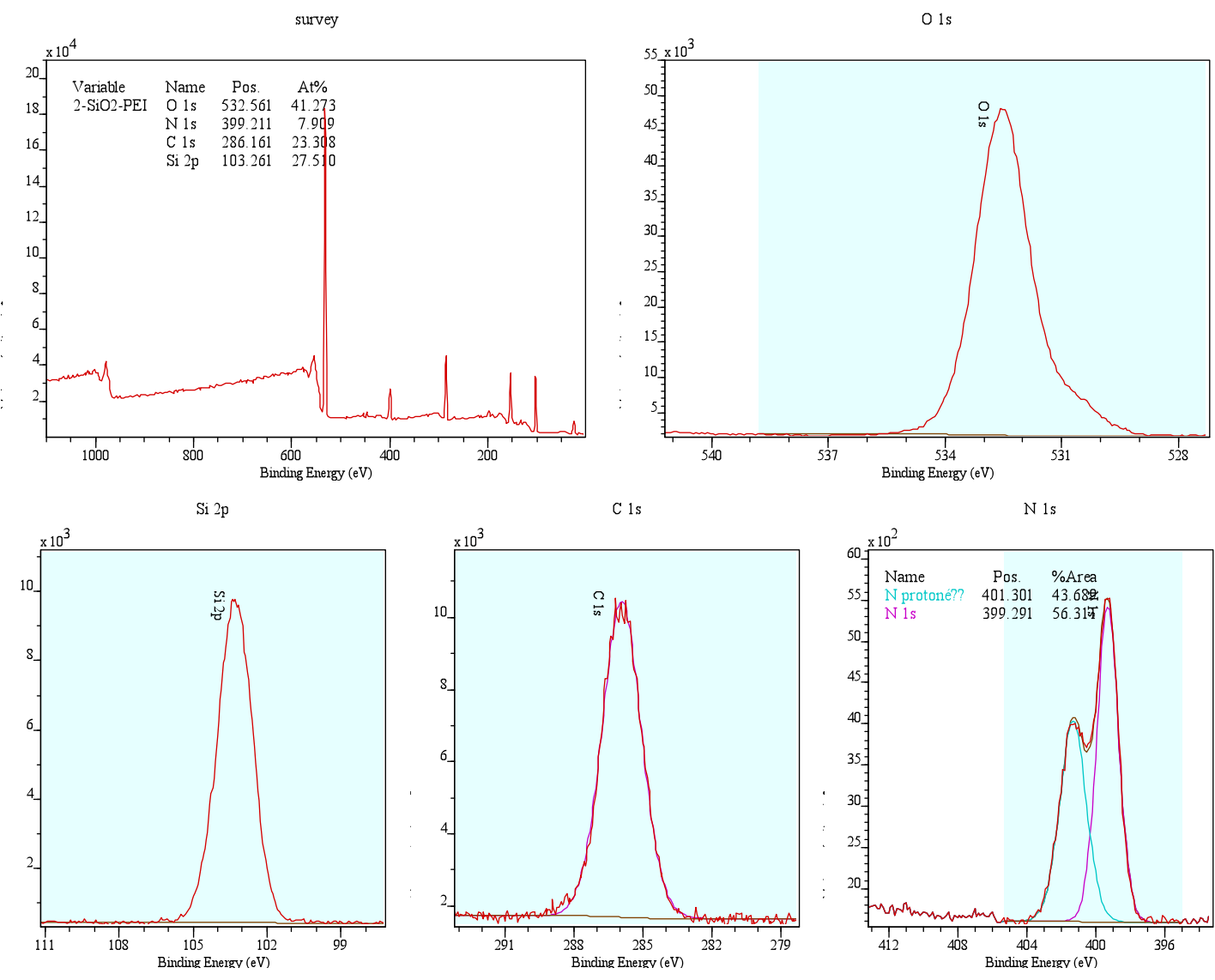

CasaXPS (This string can be edited in CasaXPS.DEF/PrintFootNote.txt) 
$\mathrm{SiO}_{2}-\mathrm{SO}_{3}$
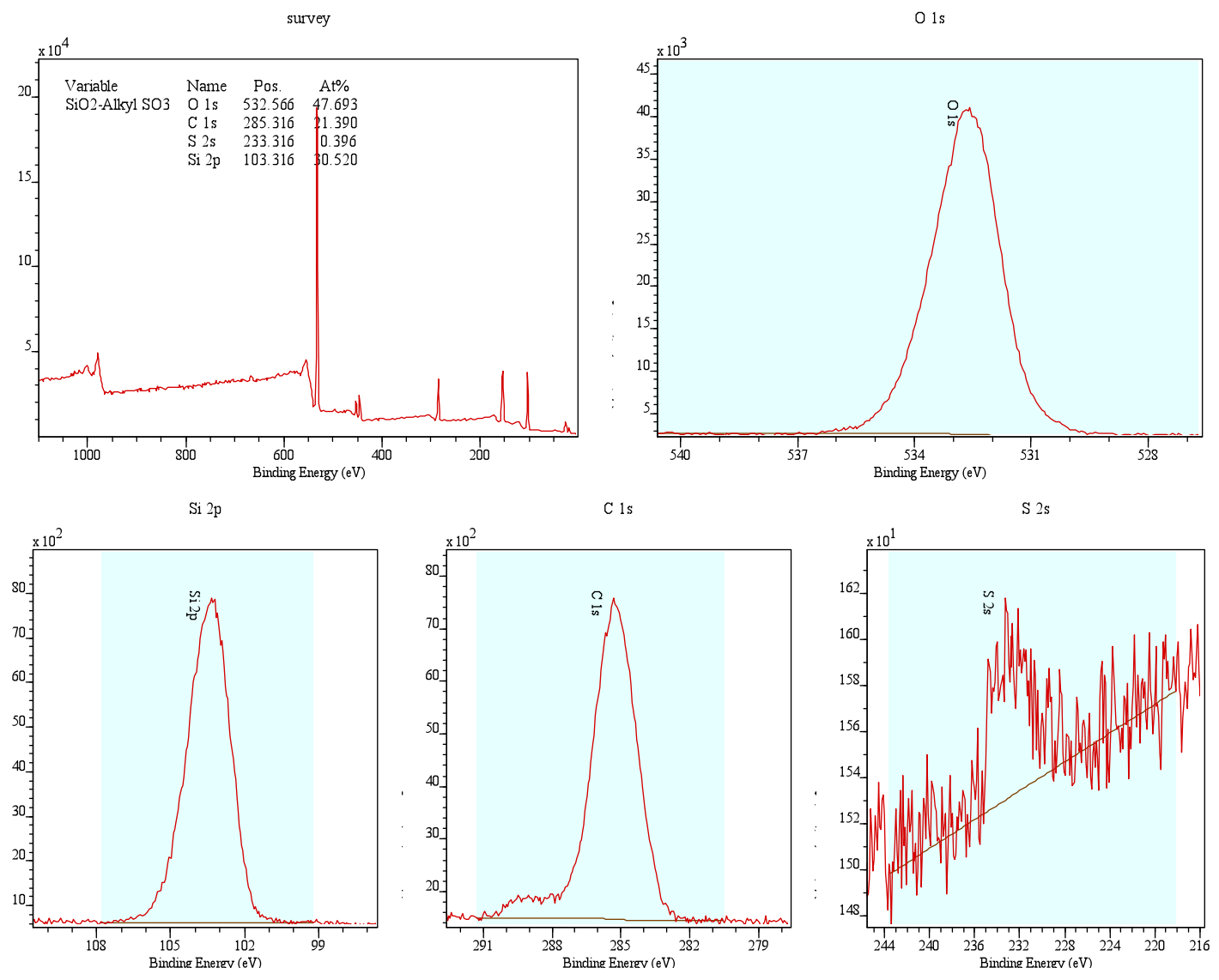


\section{$\mathrm{SiO}_{2}-\mathrm{SO}_{3} @ \mathrm{PEI}$}
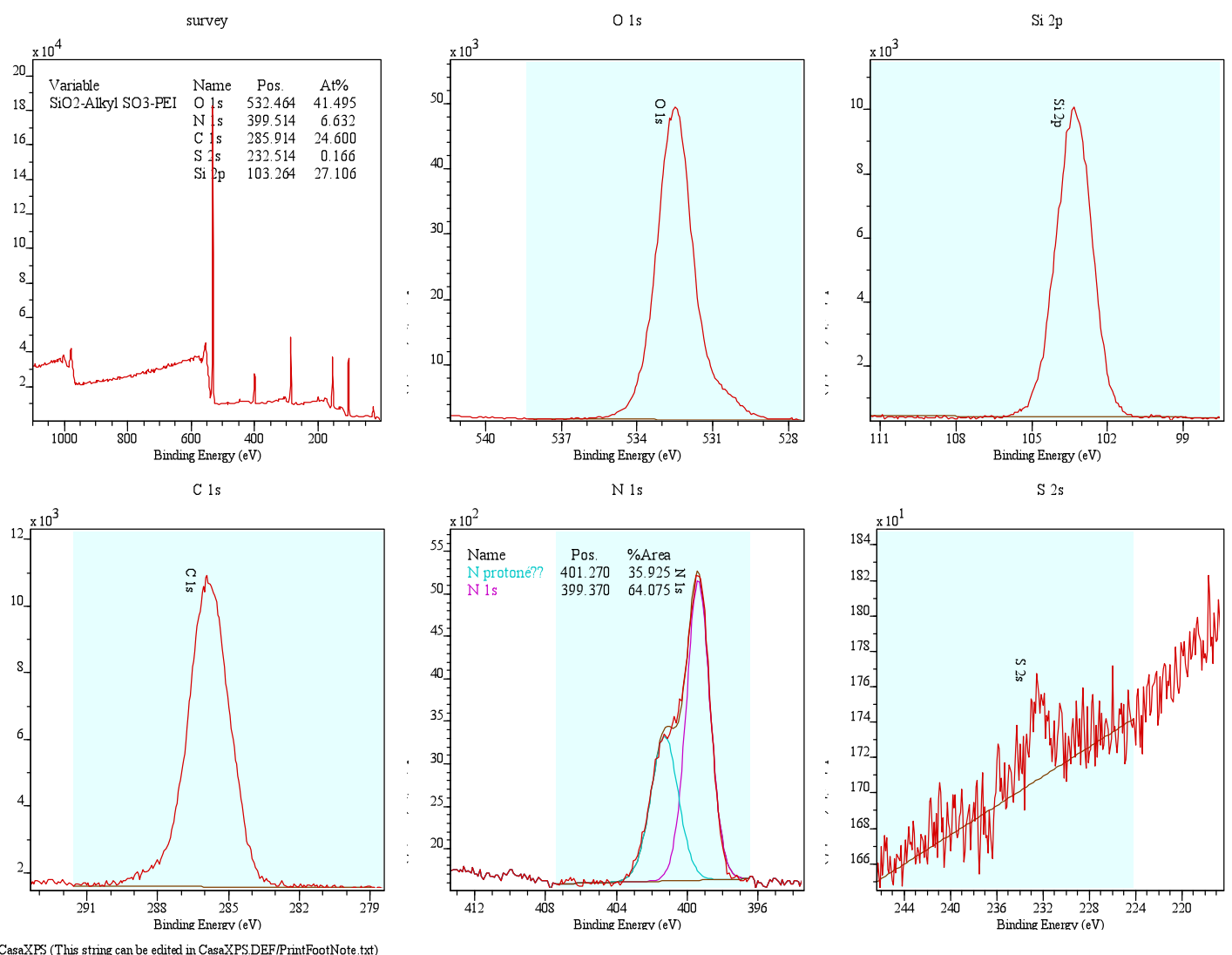


\section{$\mathrm{SiO}_{2}-\mathrm{Cl}$}
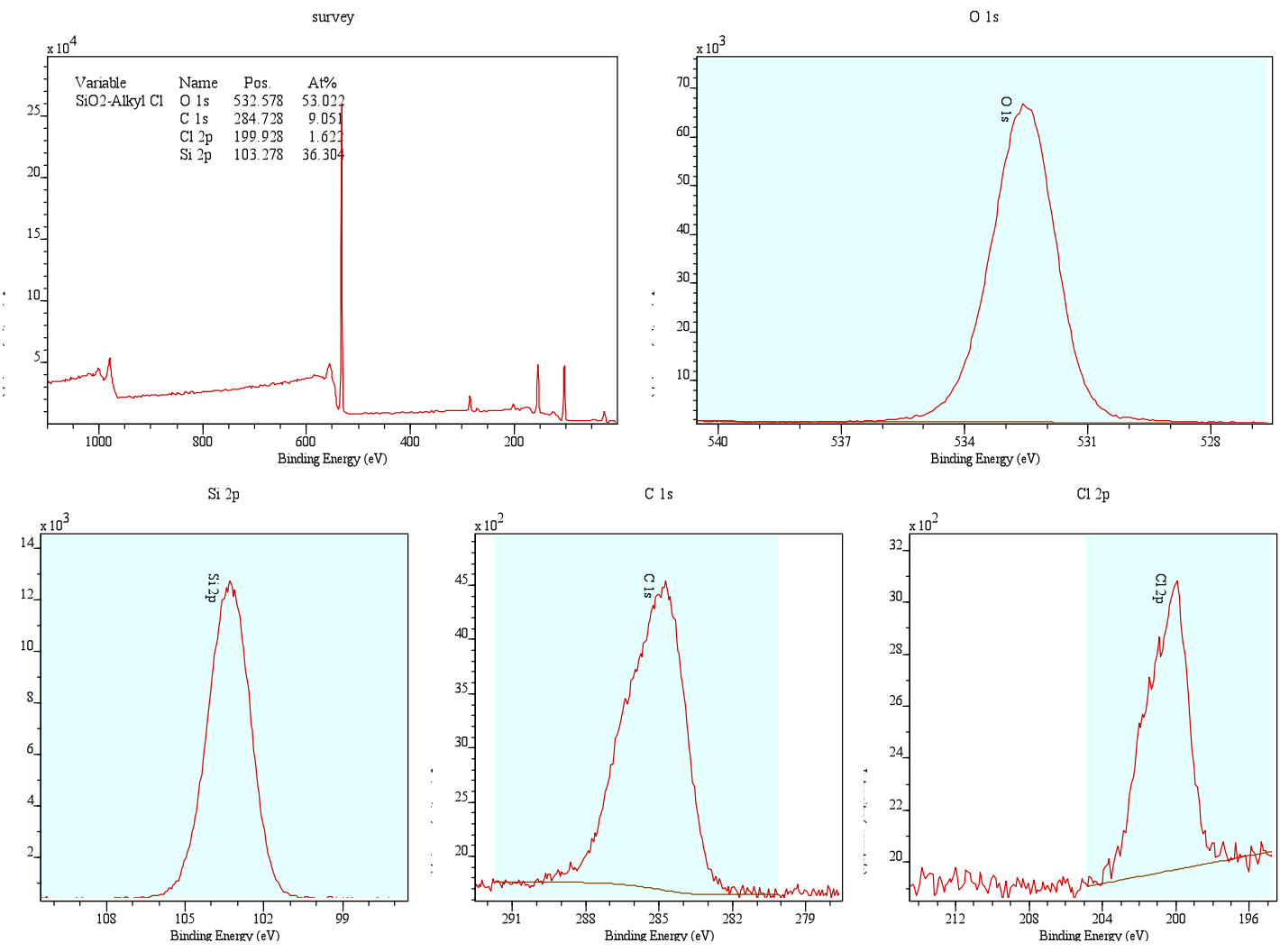

CasaXPS (This string can be edited in CasaXPS.DEF/PrintFootNote. txt) 


\section{$\mathrm{SiO}_{2}$-Cl@PEI}
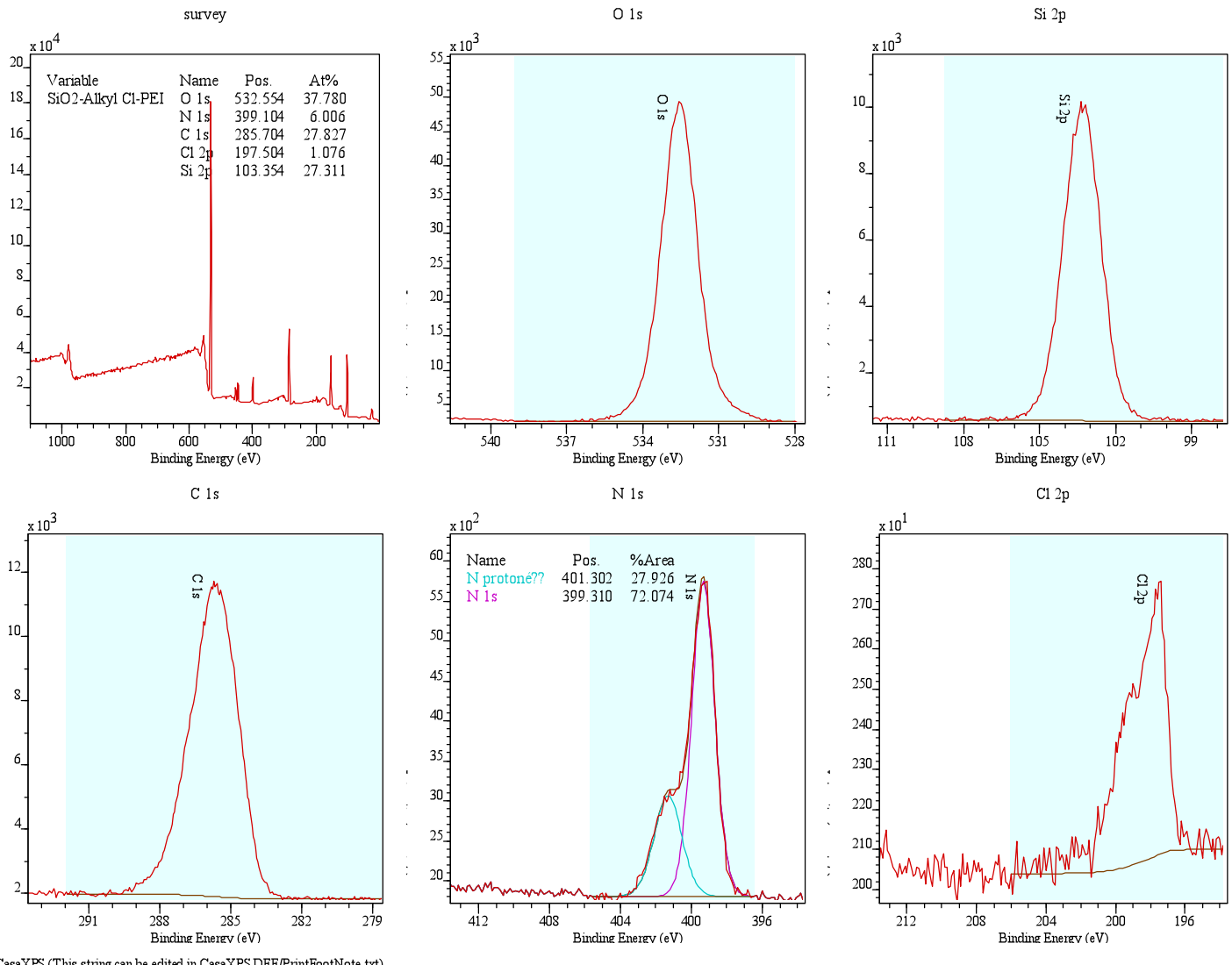
Figure S3. Agarose gel electrophoresis showing the influence of PEI conjugation mode on pGLuc complexation. A constant amount of pGLuc was complexed with particles at $1: 3,1: 10,1: 30$ and 1:50 weight ratios.

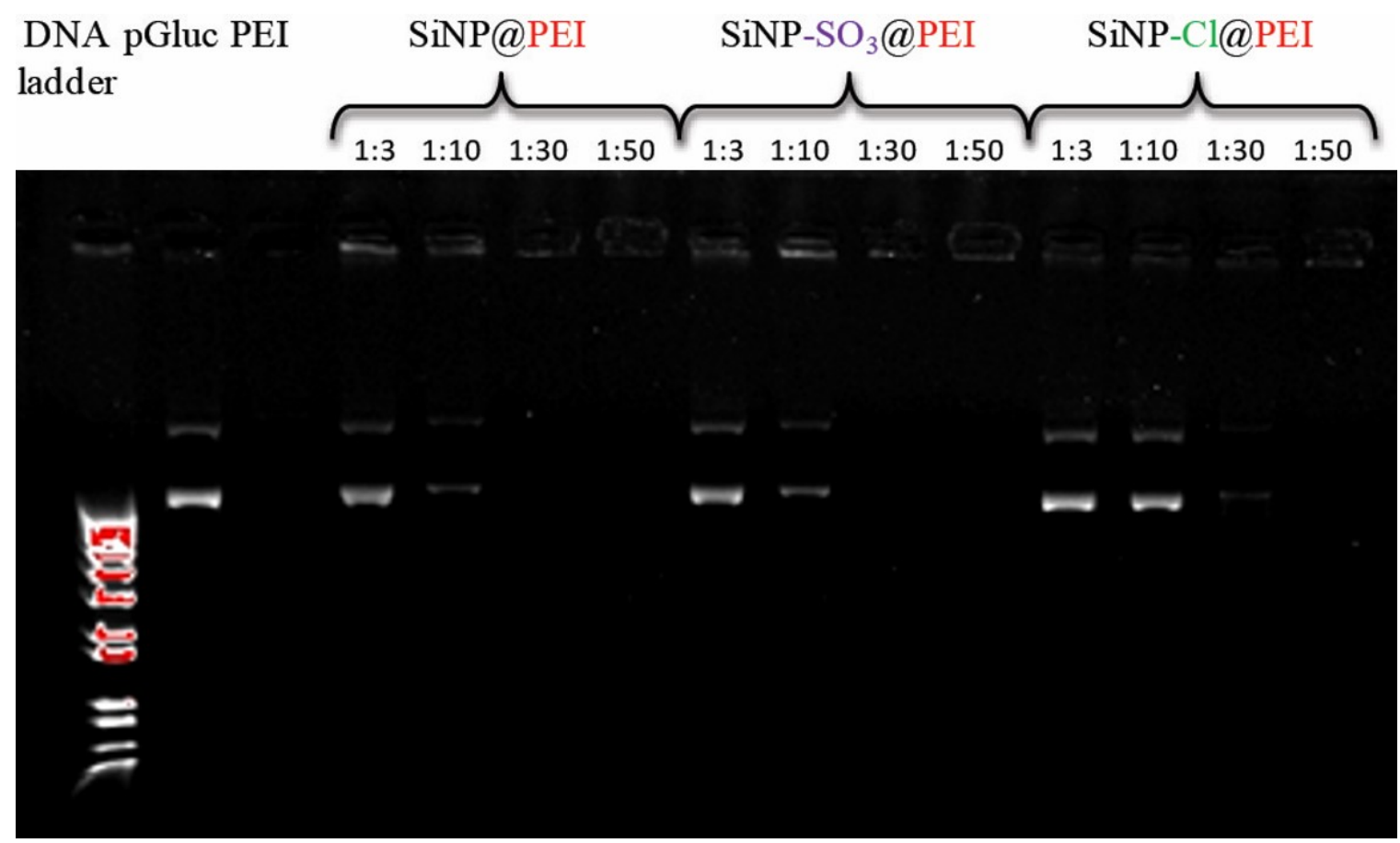


Figure S4. ${ }^{13} \mathrm{C}$ Inversion recovery cross polarization (IRCP)-MAS NMR spectra of (a) $\mathrm{SiO}_{2}-\mathrm{Cl}$ and (b) $\mathrm{SiO}_{2}$-Cl@PEI. Main acquisition parameters used for the IRCP exp.:

Recycle time: 1s; contact time: 1ms; NS: 4096; ro: $5 \mathrm{kHz}$; inversion time $\mathrm{t}_{\mathrm{i}}$ (from top to bottom): $5,10,20,30,50,70,100,200,300,500,700,1.000,3.000,5.000,10.000 \mu s$. In $\mathrm{SiO}_{2}-\mathrm{Cl}$, the signal of the $\mathrm{C}(3)$ in $\alpha$ position of the $\mathrm{Cl}$ atom reverses for an inversion time of 200-300 us; in $\mathrm{SiO}_{2}$-Cl@PEI, the C(3) signal reverses for an inversion time of 50-70 $\mu$ s. The faster cross-polarization rate indicates a decrease in mobility of the $C(3)$ upon interaction with PEI (D.G Cory, W.M. Ritchey, Macromolecules, 1989, 22, $1611-16615)$

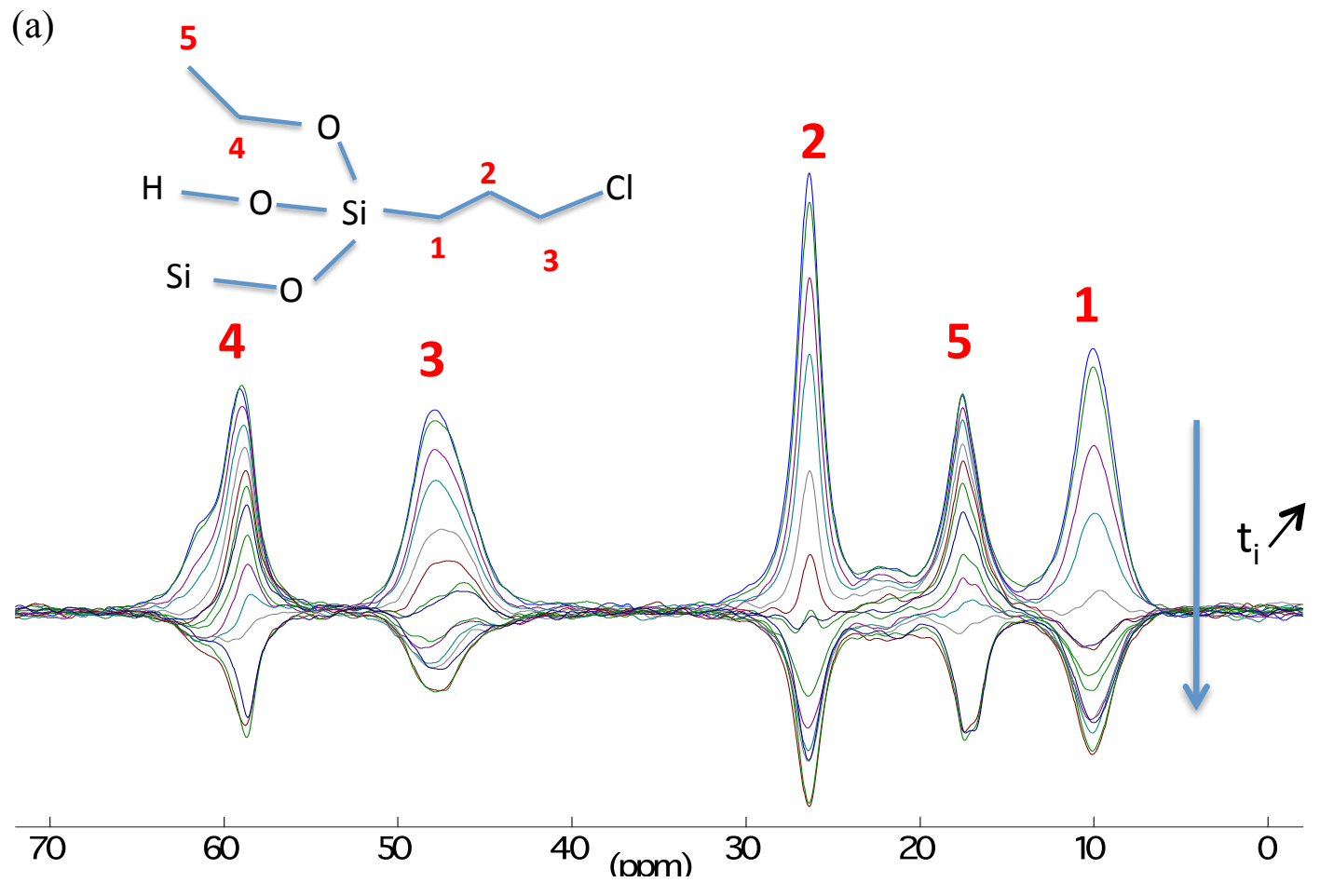




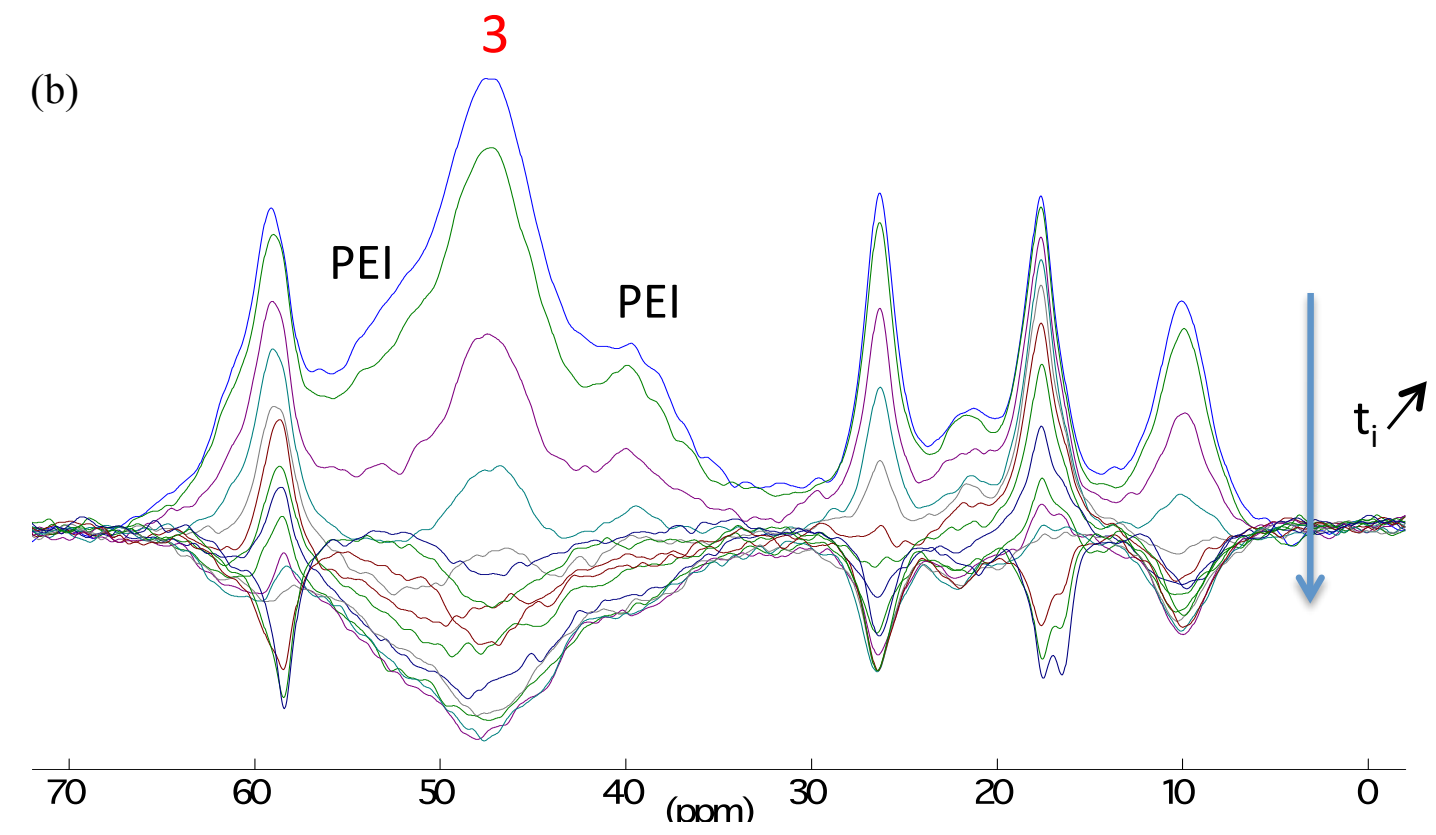


Figure S5. Viability of 3T3 fibroblast cells at the end of the transfection experiments, as determined by the Alamar Blue assay

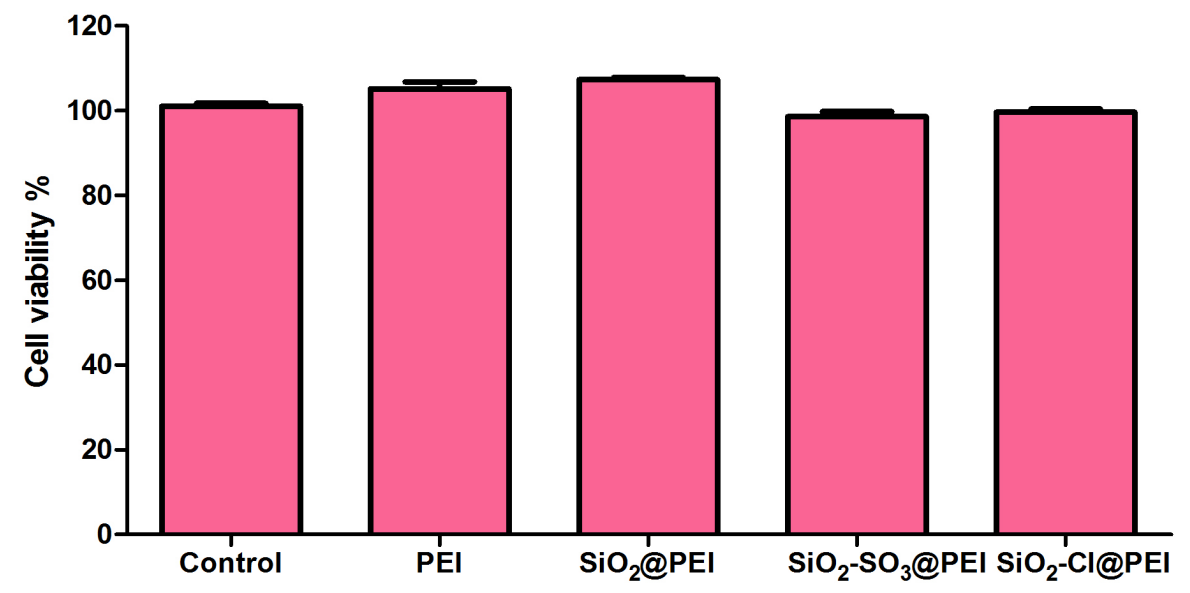

